\title{
War Signals: A Theory of Trade, Trust, and Conflict
}

\author{
DOMINIC ROHNER \\ University of Lausanne \\ MATHIAS THOENIG \\ University of Lausanne \\ and \\ FABRIZIO ZILIBOTTI \\ University of Zurich
}

First version received July 2011; final version accepted November 2012 (Eds.)

\begin{abstract}
We construct a theory of persistent civil conflicts, where persistence is driven by the endogenous dynamics of inter-ethnic trust and trade. In times of peace, agents belonging to two groups are randomly matched to trade bilaterally. Trade hinges on trust and cooperation. The onset of conflict signals that the aggressor has a low propensity to cooperate, harming future trust and trade. Agents observe the history of conflicts and update their beliefs over time. The theory predicts that civil wars are persistent. Moreover, even accidental conflicts that do not reflect economic fundamentals erode trust, and can plunge a society into a vicious cycle of recurrent conflicts (a war trap). The incidence of conflict can be reduced by policies abating cultural barriers, fostering inter-ethnic trade and human capital, and shifting beliefs. Coercive peace policies, such as peacekeeping forces or externally imposed regime changes, have no enduring effects.
\end{abstract}

Key words: Beliefs, Civil war, Conflict, Cooperation, Cultural transmission, Ethnic fractionalization, Human capital, Learning, Matching, Peacekeeping, Stochastic war, Strategic complementarity, Stag hunt game, Trade

JEL Codes: D74, D83, O15, Q34

\section{INTRODUCTION}

More than 16 million people are estimated to have died because of civil conflicts in the second half of the 20th century (Fearon and Laitin, 2003). Civil conflicts are persistent: 68 percent of all outbreaks took place in countries where multiple conflicts were recorded (Collier and Hoeffler, 2004). DeRouen and Bercovitch (2008) document that more than three quarters of all civil wars stem from enduring rivalries among ethnic groups that enter repeatedly into conflicts with each other. Weak institutions likely are part of the explanation, but are not the sole cause. Democracy, for instance, appears to have no systematic effect on the risk of civil war after controlling for other factors such as ethnic diversity, GDP per capita, and natural resource abundance 1 Moreover, several developing countries with relatively solid institutions experience recurrent

1. See, e.g. Fearon and Laitin (2003), Collier and Hoeffler (2004), Montalvo and Reynal-Querol (2005), Collier and Rohner (2008), Collier et al. (2009), and Esteban et al. (2012). 
conflicts, whereas some other countries with weak institutions and deep ethnic cleavages never see civil conflicts 2

In this article, we propose a theory arguing that trust is a main determinant of civil conflict, and that inter-ethnic trade is the channel linking the dynamics of trust and conflict. On the one hand, conflict disrupts business relationships among the groups involved. A thriving inter-ethnic trade, therefore, deters war by raising the opportunity cost of war. On the other hand, trade hinges on trust, since inter-ethnic partnerships (e.g. seller-buyer, employer-employee, supplier-producer, lender-borrower relationships) typically go beyond spot transactions. By fostering trade, trust deters civil conflict.

We formalize our ideas through a dynamic model in which agents belonging to two ethnic groups are randomly matched to engage in bilateral partnerships (trade), which we model as a variant of the classic stag hunt game augmented with individual heterogeneity in the propensities to cooperate. There are strategic complementarities: the proportion of cooperators in each group increases in the perceived trustworthiness of the other group. Over time, beliefs get updated based on public signals (and, in an extension, on private information acquired by traders) and transmitted across generations. Finally, one group can wage war against the other, at the cost of destroying trade in the current period. Conflict undermines future trust by signalling to the victimized group that the aggressor has a low propensity to trade cooperatively. Thus, a war today carries the seed of distrust and future conflict.

The theory yields two main predictions that are borne out in the data. First, civil wars are persistent: each outbreak of conflict increases the probability that a country will fall again into civil war in the future. Imperfect and, possibly, incorrect learning is the source of endogenous persistence. Second, trust is negatively correlated with civil conflict. The causation runs both ways: war causes trust and trade to plummet; conversely, low trust and scant inter-ethnic trade increase the probability of future wars. "Accidental wars", e.g. aggressions initiated by a belligerent minority of a group, or conflicts triggered by exogenous factors (such as a lower threat of international sanctions against aggressors) may lead to the permanent breakdown of peace (a war trap). War traps are characterized by endemic conflict and low inter-ethnic cooperation even during peace spells.

In the benchmark model, we introduce a number of simplifications to achieve a sharp characterization of the dynamic equilibrium. In Section 6 we relax some of the assumptions. First, we consider shocks affecting over time the groups' propensity to cooperate. Second, we extend the analysis to a richer and more realistic environment where traders acquire private information throughout their business experience about the other group's type. These and other extensions show that war traps is a robust result. In addition war cycles, i.e. periods of endemic recurrent wars followed by more peaceful periods, can arise.

The analysis yields a number of policy implications. First, policies increasing the profitability of inter-ethnic trade reduce the incidence of conflict. Examples include policies abating barriers, such as educational policies promoting the knowledge of several national languages, or subsidies for human-capital investments. Second, policies directly targeting people's held beliefs may be useful. These include educational campaigns promoting civic values and cross-group empathy, as well as repressive interventions outlawing the diffusion of hateful messages demonizing other

2. Columbia, India, Turkey, Sri Lanka, and the Philippines fare relatively well in terms of democracy and other institutional indicators, conditional on their stage of development. Yet, they are prone to civil conflicts. Interestingly, these countries have a lower average level of trust than the average non-OECD country ( 0.16 vs. 0.22$)$. On the opposite front, Bhutan, Cameroon, Gabon, Kazahstan, Togo, China, and Vietnam have low scores on democracy and high ethnic fractionalization, but no recent history of civil war. Data on trust are available only for China and Vietnam among these countries. Their average trust is 0.51 , even larger than in the average OECD country. 
TABLE 1

Persistence of civil conflicts and correlation between conflict and lagged trust (frequency: five-years)

\begin{tabular}{|c|c|c|c|c|c|c|c|c|c|c|}
\hline & (1) & (2) & (3) & (4) & (5) & (6) & (7) & (8) & (9) & (10) \\
\hline War $(t-1)$ & $\begin{array}{l}0.36^{* * * *} \\
(0.01)\end{array}$ & $\begin{array}{l}0.22^{* * *} \\
(0.01)\end{array}$ & $\begin{array}{l}0.30^{* * *} \\
(0.02)\end{array}$ & $\begin{array}{l}0.17^{* * *} \\
(0.01)\end{array}$ & $\begin{array}{l}0.32^{* * *} \\
(0.02)\end{array}$ & $\begin{array}{l}0.17^{* * *} \\
(0.02)\end{array}$ & $\begin{array}{l}0.24^{* * *} \\
(0.04)\end{array}$ & $\begin{array}{c}0.10 \\
(0.07)\end{array}$ & $\begin{array}{l}0.24^{* * *} \\
(0.02)\end{array}$ & $\begin{array}{c}0.05 \\
(0.04)\end{array}$ \\
\hline Trust $(t-1)$ & & & & & & & $\begin{array}{r}-0.37^{*} \\
(0.21)\end{array}$ & $\begin{array}{c}-0.56^{\text {**** }} \\
(0.20)\end{array}$ & $\begin{array}{c}-0.48^{* * *} \\
(0.08)\end{array}$ & $\begin{array}{l}-0.46^{* * *} \\
(0.17)\end{array}$ \\
\hline $\begin{array}{l}\text { Conflicts coded } \\
\text { as war }\end{array}$ & > 25 Fat. & > 1000 Fat. & $>25$ Fat. & > 1000 Fat. & $>25$ Fat. & > 1000 Fat. & $>25$ Fat. & > 1000 Fat. & $>25$ Fat. & $>1000$ Fat. \\
\hline Controls & No & No & Yes & Yes & Yes & Yes & Yes & Yes & Yes & Yes \\
\hline Sample & All & All & All & All & WVS & WVS & WVS & WVS & WVS & WVS \\
\hline Observations & 1426 & 1426 & 1026 & 939 & 409 & 378 & 101 & 101 & 564 & 439 \\
\hline Pseudo $R^{2}$ & 0.304 & 0.322 & 0.363 & 0.358 & 0.460 & 0.392 & 0.575 & 0.572 & 0.695 & 0.597 \\
\hline
\end{tabular}

Dependent variable: Civil war incidence (five-year intervals). The dependent variable is coded as 1 if a conflict causing at least 25 (1000) fatalities is recorded in at least one of the five years. Sample period: 1949-2008. Number of countries for which observations are available: 174. The set of controls include: lagged democracy, lagged GDP per capita, oil exporter, lagged population, ethnic fractionalization, mountainous terrain, noncontiguous state, region fixed effects and time dummies. Columns 5 and 6 restrict the sample to only the 61 countries for which at least one trust observation is available. Columns 9 and 10 have as dependent variable civil war incidence at the annual level (details in the text). The table reports the marginal effects of logit regressions with robust standard errors, clustered at the country level. Significance levels: ${ }^{*} p<0.1,{ }^{* *} p<0.05,{ }^{* * *} p<0.01$.

groups. Likewise, interventions designed to nurture and foster cohesive values (e.g. national over ethnic identity) can be important. Credible campaigns documenting and publicizing success stories of inter-ethnic business relationships, joint ventures, and so on, are other relevant examples. On the contrary, attempts to impose peace through coercion-e.g. peacekeeping forces or externally imposed regime changes - ultimately have no persistent effects, especially if they fail to restore trade links. Forcing the separation of groups may even be harmful, since such measures would stifle any potential for trade cooperation that otherwise may emerge during peace spells, and that over time may slowly restore confidence. These predictions are consistent with empirical studies in the conflict literature, which we discuss in more detail below.

\subsection{Motivating evidence}

We start by documenting that conflicts are highly persistent. We construct an indicator of civil war incidence taking on the unit value in each five-year interval during which a country experiences a civil conflict causing at least 25 casualties in a single year. The source data (originally at the annual level) are from the "UCDP/PRIO Armed Conflict Dataset" (UCDP, 2012) 3 We use a panel of 174 countries in the sample period 1949-2008. We run an autoregressive pooled logit regression of civil war incidence on its lagged value. Table 1 reports the marginal effects of the main variables of interest. The Supplementary Appendix A provides the complete set of regression results.

We find that a country experiencing war in the five-year period $t-1$ has a 36 percentage points higher probability of experiencing war in the five-year period $t$ than a country that did not experience war at period $t-1$ (Column 1). The autoregressive coefficient is highly significant $(>1 \%)$. We see similar results if we code as civil wars only conflicts causing at least a thousand fatalities in a single year (Column 2). Since the persistence in conflict could be driven by persistent differences in institutional or political factors, we add controls for a standard set of explanatory variables used in the conflict literature; see, e.g. Fearon and Laitin (2003), Collier and Hoeffler (2004), Montalvo and Reynal-Querol (2005), Cederman and Girardin (2007), Collier and Rohner 
(2008), and Esteban et al. (2012). In particular, we control for an index of democracy, natural resources (oil), population, an index of ethnic fractionalization, geography (i.e. the proportion of mountainous terrain and a dummy for non-contiguous states), and the lagged GDP per capita. In addition, we control for time dummies and regional fixed effects. The marginal effects are affected only slightly by the control variables, and remain highly statistically significant (Columns 3 and 4). The results are robust also to country fixed effects (see Table 2, Columns 11-12 in Supplementary Appendix A), which absorb the effect of any time invariant heterogeneity, consistent with the results of Martin et al. (2008b). Therefore, the result is not driven by persistent differences in institutional factors that make some countries more prone to war.

Next, we document that civil war incidence is negatively correlated with a lagged measure of trust from the World Values Survey (2011). Trust is measured by the proportion of respondents answering "Most people can be trusted" to the question: "Generally speaking, would you say that most people can be trusted or that you need to be very careful in dealing with people?" (A165) 4 This is a coarse measure from our perspective, since it does not focus specifically on the inter-ethnic dimension. However, we expect it to be positively correlated with inter-ethnic trust. Lagged trust is coded as the average trust level across all World Values Survey (WVS) observations available in the five-year interval preceding the interval in which the dependent variable is measured. First, since adding trust to the regressions causes a major reduction in the sample size, we document that the results of Columns 3 and 4 are robust to restricting the sample to the 61 countries in the WVS for which at least one trust observation is available (Columns 5 and 6). Second, Columns 7 and 8 show that the effect of lagged trust is negative and statistically significant (note that the sample falls further to 101 observations, since even in the restricted sample of 61 countries there is an average of only 1.7 observations per country). The effect is quantitatively large: a one standard deviation increase in lagged trust is associated with a fall in the probability of conflicts of 5.2 percentage points for all wars (Column 7), and of 7.9 percentage points for big wars (Column 8). It is not possible to run this specification with country fixed effects: there are only six countries - totaling sixteen observations - that have both multiple observations of lagged trust and variation in the war variable for the periods in which lagged trust is available. The results are robust to exploiting the variation of conflict at the annual frequency. In Columns 9 and 10, we repeat the regressions in Columns 7 and 8 using annual variables, with two qualifications. First, lagged trust continues to be the average across all observations available in the five years preceding the observation of the dependent variable 5 Second, we continue to measure the lagged war dummy also over a five-year interval, since it is plausible that civil wars have a persistent effect on the probability of future conflict that exceeds the one-year horizon 6 The results are robust: war is persistent, and high trust is associated with a significantly lower probability of future war 7

4. In our sample, an average $27.9 \%$ of all respondents in a given country and five-year period declare that they generally trust others (with a s.d. of 14.2\%). Moreover, $23.2 \%$ of country five-year period observations experience either a minor or a major conflict, whereas only $9.7 \%$ of all country five-year periods experience a major war.

5. This choice is motivated mainly by data limitations: The WVS does not provide yearly surveys. We also considered alternative measures of lagged trust where (i) we take the average over the past ten years, and (ii) we use only the most recent available survey. In both cases, the results are robust.

6. The results are robust to a number of alternative specifications including (i) replacing the lagged war dummy with a variable counting the number of wars over the past five years; (ii) augmenting the specification discussed in the text with a dummy switching on if, in the year before the observation of the dependent variable, there was a civil conflict; (iii) lagged war is measured over a ten-year instead of a five-year window.

7. If we use a measure of ethnic polarization instead of fractionalization, the coefficients of lagged war and lagged trust remain statistically significant in every column and of the same magnitude. Analogously, all results are robust to controlling for diamond production. 
Most control variables have the expected sign (see Tables 2 and 3 in Supplementary Appendix A), although they are significant only in some of the specifications. Consistent with the literature, we find that countries that are oil exporters, and have large ethnic fractionalization, a large population, a high proportion of mountainous terrain, and non-continguous territory tend to experience more conflict. Democracy has no robust effect on the risk of conflict. Its sign changes across specifications and is often insignificant.

Although we use lagged trust as a right-hand side variable, we do not claim to identify causal effects of trust on civil wars. To do so would require credible exclusion restrictions that are difficult to find. Moreover, our theory predicts that the causality runs both ways: while distrust increases the probability of civil conflict, war erodes cross-community trust. Evidence of the latter effect is documented by a number of empirical case studies. For instance, in a companion empirical paper (Rohner et al., 2011), we study the effect of civil conflict on trust and other measures of social capital in Uganda. We find that an exogenous outburst of ethnic conflicts in 2002-2005 driven by an international shock (the US administration's change of policy against insurgent movements after the terrorist attack of 9/11), had a large negative effect on trust. On the one hand, districts and counties that were subject to more intense fighting experienced a decline in general trust relative to areas where fighting was lighter. On the other hand, conditional on the extent of regional violence, trust fell in relative terms for ethnic groups that were directly involved in fighting. Similar findings are documented by Cassar et al. (2011), who conduct experiments and surveys in Tajikistan after the end of the 1992-1997 civil war. They find that exposure to conflict reduced significantly trust within local communities.

In our theory, the channel linking war and trust is inter-ethnic trade. While the effect of international trade on both civil and international wars is well documented (see, e.g. Martin et al., $2008 \mathrm{a}, \mathrm{b}$ ), it is more difficult to find systematic data on trade within-country between different communities. However, the evidence from a number of case studies conforms well with the predictions of our theory. We return to the discussion of the case-study evidence in Section 7

\section{2. $\quad$ Related literature}

This article connects to various streams of economic literature. The link between trust, social norms, specific investments, and business relationships is emphasized by a large body of literature on contractual incompleteness. The salience of this issue in the context of cross-community trade is emphasized by Dixit (2003). In Hauk and Saez-Marti (2002) and Tabellini (2008) pro-social norms preventing opportunistic behaviour are key to sustaining efficient trade.

Learning traps are related to the literature on herding, social learning, and informational cascades. This includes Banerjee (1992); Bikhchandani et al. (1992); Ely and Valimaki (2003); Fernandez (2012); and Piketty (1995). The connection with these papers is discussed in more detail in Section 5.2. The theory is related also to the theoretical literature on supermodular games with strategic complementarities (Baliga and Sjostrom, 2004; Chamley, 1999 and 2004; Chassang and Padro-i-Miquel, 2010; and Cooper and John, 1988). While most of these papers emphasize the possibility of static multiplicity, in this article we constrain parameters to yield a unique equilibrium under perfect information. The dynamic nature of the model of conflict is related to Yared (2010). The importance of luck and the persistent effects of negative shocks link our contribution to Acemoglu and Zilibotti (1997). Also related to our research are the recent papers by Aghion et al. (2010, 2011) focusing on the relation between public policy, on the one hand, and beliefs and norms of cooperation in the labour market, on the other hand.

In a recent paper, Acemoglu and Wolitzky (2012) propose a theory of conflict snowballs in which mistaken signals can trigger conflict between two groups. Their main focus is on war cycles, and specifically on how conflicts that are not driven by fundamental reasons may come to 
an end. In their model, as a bilateral conflict escalates, aggressive actions become uninformative, eventually inducing a group to experiment with cooperation. As long as the other group is not inherently bad, this move can bring the conflict to an end. Their model differs from ours in many respects - in particular, there is no explicit link between war and trade, which is the focal point of our analysis.

This article is related more generally to the economic literature on conflict (cf. Blattman and Miguel, 2010, for an extensive survey). A set of prominent papers focus on institutional failures, such as weak state capacity and weak institutions (Besley and Persson, 2010, 2011; Fearon, 2005). In Besley and Persson (2011) the lack of checks and balances implies that rent-sharing strongly depends on who is in power, thereby strengthening incentives to fight. Acemoglu and Robinson (2012) discuss the importance of inclusive political and economic institutions to avoid civil wars. Poverty and natural resource abundance also have been found to fuel conflict, as the former reduces the opportunity cost of fighting, while the latter results in a larger "pie" that can be appropriated (Torvik, 2002; Collier and Hoeffler, 2004). The importance of ethnic polarization is emphasized, among others, by Esteban and Ray (2008, 2011), Caselli and Coleman (2012) and Rohner (2011). Some theories try to explain, as we do, why civil conflicts recur. Collier and Hoeffler (2004) argue that wars increase the availability of conflict-specific capital, such as cheap military equipment, that can be used for further conflicts. Acemoglu et al. (2010) argue that in weak states civilian governments select small and weak armies in order to prevent coups. However, this makes these states more vulnerable to insurgency and rebellion.

The plan of the article is the following. Section2 2 presents the benchmark model of inter-ethnic trade and conflict. Section 3 characterizes the perfect information equilibrium, while Section 4 presents the equilibrium under asymmetric information. Section 5 extends the framework to a dynamic environment where beliefs are transmitted across generations, and derives the main results. Section 6 presents a number of extensions of the benchmark theory. Section 7 discusses some empirical evidence consistent with the predictions of the theory. Section 8 discusses some policy implications. Section 9 concludes. The proofs of all Lemmas, Propositions and Corollaries in Sections 35 are in Appendix I. The Supplementary Appendices A, B, and C contain proofs not in the text, and additional technical material.

\section{MODEL ENVIRONMENT}

The model economy is populated by a continuum of risk-neutral individuals belonging to two $e t h$ nic groups $(A$ and $B$ ), each of unit mass. The interactions between the two groups are described by a two-stage game. First, group A decides whether to wage war against group B. Next, cross-ethnic economic interactions (trade) occur. No economic decisions are made under the shadow of war. In the case of peace, each agent in group A is randomly matched to trade with an agent in group B.

Trade is modelled as a classic stag hunt game. If both trade partners in a match cooperate, a high economic surplus is generated, and each trader receives the payoff $c$. If both sides defect, each receives $d<c$. If only one side cooperates, the cooperator suffers a loss, and receives $d-l$, while the defector receives $d$. The matrix of material payoffs is:

\begin{tabular}{c|cc} 
& $C$ & $D$ \\
\hline$C$ & $c, c$ & $d-l, d$ \\
$D$ & $d, d-l$ & $d, d$
\end{tabular}

Absent other elements, the payoff matrix above describes a coordination game with multiple equilibria: C-C is a Pareto-dominant Nash equilibrium, D-D is also a Nash equilibrium. Note that defection is a "safer" strategy: if one player perceives it unlikely that the partner cooperates, she will go for the safe payoff $d$ from defection. 
The matrix above describes only part of the surplus arising from inter-ethnic partnerships. The total utility includes, in addition, a psychological component related to the compliance with existing social norms of cooperation. The salience of such norms is assumed to be heterogeneous across individuals and groups. We denote by $\mathcal{P} \in \mathbb{R}$ the psychological benefit enjoyed by an agent from playing cooperatively, irrespective of his opponent's action. Then, the matrix of total payoffs is given by

\begin{tabular}{c|cc} 
& $C$ & $D$ \\
\hline$C$ & $c+\mathcal{P}_{i}, c+\mathcal{P}_{j}$ & $d-l+\mathcal{P}_{i}, d$ \\
$D$ & $d, d-l+\mathcal{P}_{j}$ & $d, d$
\end{tabular}

The heterogeneity reflects the fact that individuals enjoy cooperation to varying extents. Agents with high $\mathcal{P}$ exhibit strong civic norms. When $\mathcal{P}>l$, the norm is so strong that the player would even cooperate with a partner known to defect. However, $\mathcal{P}$ can be low and even negative, indicating hatred, i.e. pleasure from inflicting losses to a member of the other group. The distribution from which $\mathcal{P}$ is drawn is assumed to be group specific: for example, a more clannish group may be on average less inclined to cooperate with strangers.

More formally, $\mathcal{P}$ is assumed to be a continuous random variable, i.i.d. across agents in each group, and drawn from a probability density function (p.d.f.), $h^{J}: \mathbb{R} \rightarrow \mathbb{R}^{+}$, where $J \in\{A, B\}$, which is assumed to have no mass points. We denote by $H^{J}: \mathbb{R} \rightarrow[0,1]$ the corresponding cumulative distribution function (c.d.f.). Group A can be of two types: $h^{A} \in\left\{h^{+}, h^{-}\right\}$, and accordingly $H^{A} \in\left\{H^{+}, H^{-}\right\}$, where $H^{+}$first-order stochastically dominates $H^{-}$. Since $\mathcal{P}$ reflects the propensity to cooperate with the other group, we say that group A is trustworthy (or civic) when $H^{A}=H^{+}$, and not trustworthy (or uncivic) when $H^{A}=H^{-}$. Instead, we assume that $H^{B}$ has a unique realization. This is for tractability, as it avoids complications arising from a multidimensional learning process. We denote by $k \in\{-,+\}$ the type of group A. Note that throughout the article we refer to a group's type as a particular cross-sectional distribution of attitudes towards cooperation, rather than as the propensities of specific individuals (which vary within each group). Therefore, the assumption that $H^{B}$ has a unique realization means that group B's type is common knowledge, whereas group B ignores whether $H^{A}=H^{+}$or $H^{A}=H^{-}$. It is useful to rescale some variables in order to simplify computations.

Notation 1. Let (i) $z \equiv c-(d-l) ; \quad$ (ii) $\mathcal{L}_{i} \equiv l-\mathcal{P}_{i} ; \quad$ (iii) $f^{J}(\mathcal{L}) \equiv h^{J}(l-\mathcal{L})$ and $F^{J}(\mathcal{L}) \equiv 1-$ $H^{J}(l-\mathcal{L})$, with $J \in\{+,-, B\}$.

Intuitively, $z$ is the payoff difference for a cooperator when its opponent switches from defecting to cooperating. $\mathcal{L}_{i}$ is the payoff difference (including psychological benefits) between cooperating and defecting, when the opponent turns out to be a defector. The group-specific p.d.f. and c.d.f. of $\mathcal{L}$ are simple transformations of the respective p.d.f. and c.d.f. of $\mathcal{P}$.

Finally, we introduce a technical assumption that is maintained throughout the rest of the article.

Assumption 1. There exists $\varepsilon>0$ such that the p.d.f. $f^{B}(\mathcal{L}), f^{+}(\mathcal{L})$ and $f^{-}(\mathcal{L})$ are nondecreasing in the subrange $\mathcal{L} \in[-\varepsilon, z+\varepsilon[$.

Assumption 1 requires that, at least in the interval $\mathcal{P} \in[-(c-d), l]$, there are no more people with high than with low civic norms. As explained below, this is a sufficient condition to guarantee existence and uniqueness of the equilibrium in the trade game. 


\subsection{Interpretation}

The trade game with social norms, 10, is related to Hauk and Saez-Marti (2002) and Tabellini (2008). We assume, as they do, that individuals drawn from different populations are randomly matched to form business partnerships, and that there is individual heterogeneity in norms and taste for cooperation. However, in their models social norms of good conduct are endogenous and evolve according to parental cultural transmission. In our model, we take norms as exogenous and emphasize, instead, the effects of asymmetric information about a group's propensity to cooperate, or its trustworthiness in the other group's eyes. Cooperation is inherently risky, and defection can be motivated by the drive to play it safe against a distrusted partner. For instance, an efficient partnership may require one trader (the producer) to deliver goods to a partner (the middleman) in exchange for a deferred payment (e.g. the middleman can be credit constrained and unable to pay the producer before selling the good). However, if the middleman's group is reputed to be prone to defection, the producer may refrain from entering into the arrangement. Due to the strategic complementarity in the trade game, the public reputation of group A affects the behaviour of group B: if group A is perceived to be little trustworthy, for instance, its members will expect that many agents in group B will defect, and will themselves defect.

Finally, we note that the normal-form game, 11, is susceptible to an alternative interpretation that abstracts from norms and psychological payoffs. Suppose that the success of an inter-ethnic business opportunity requires that both partners make a costly pre-trade investment (in physical or human capital) such as familiarizing oneself with the other group's language and customs, or building an inter-ethnic trade network. The investment cost is heterogeneous across agents and equal to $\mathcal{L}_{i} \equiv l-\mathcal{P}_{i}$. When both partners invest, they can trade and earn each a payoff $c$. Otherwise, there is no trade and agents receive a default payoff $d$. In this context, cooperation and defection correspond to investing and not investing, respectively, before random matching. The payoff matrix is observationally equivalent to (1).

While in our discussion we emphasize the notion of trade, which we believe to be especially important, the gist of our argument extends to a broader set of inter-ethnic social interactions within countries. These can include inter-ethnic marriages, public good provision in villages and communities, and more general situations involving bilateral cooperation.

\subsection{Stochastic wars}

We denote by $\mathcal{V}$ the net benefit of war accruing to group A, comprising both the value of the resources seized in war and any military or psychological costs associated with war. While, for simplicity, we do not model explicitly the conflict dynamics, $\mathcal{V}$ can be interpreted as the expected payoff of a war with an uncertain outcome. We make the important natural assumption that $\mathcal{V}$ is a stochastic variable 8 Shocks to $\mathcal{V}$ reflect shifts in a variety of factors affecting the cost and the risk of military operations. These include the amount of expropriable resources (or, to the opposite, the losses in case of defeat), the internal cohesion of the group, the state of organization and morale of the army, and international factors such as the willingness of the international community to impose sanctions on the aggressor. An important assumption is that the realization of $\mathcal{V}$ cannot be (perfectly) observed by group B. For instance, the state of efficiency of the Soviet army after the 1936 purges was uncertain to its enemies. Its weaknesses became patent (and even exaggerated) after the poor performance of the Red Army in the Winter War against Finland.

8. Our assumptions echo the recent literature that views the onset of war as "stochastic" (Gartzke, 1999; Caselli et al., 2012), in particular due to stochastic shocks to coordination costs of rebellion (Collier and Hoeffler, 1998), or to rebel capability (Gates, 2002; Buhaug et al., 2009). 
The decision to wage war is driven by the comparison between the realization of $\mathcal{V}$ and the aggregate trade surplus accruing to group A in case of peace, denoted by $S^{k}$ with $k \in\{+,-\}$. Note that $S^{k}$ corresponds to the sum of all the payoffs from trade obtained by the whole population of group A, given the payoff matrix 1 the distribution of psychological benefits $\mathcal{P}$ from cooperation, and the proportions in both groups of agents cooperating. $S^{k}$ is endogenous and will be determined in equilibrium. We will show below that $S^{k}$ is bounded, $S^{k} \in\left[S^{\min }, S^{\max }\right]$. Although different members of group A might disagree about the desirability of war, depending on the individual realization of $\mathcal{P}$, we assume that group $A$ has access to internal transfer mechanisms that compensate losers. Thus, the decision to go to war weighs the expected benefit $\mathcal{V}$ against the total opportunity cost of war to group A 9

Finally, to ease tractability, we discretize the support of the distribution of $\mathcal{V}$, allowing for three possible realizations, $\mathcal{V} \in\left\{V_{L}, V, V_{H}\right\} 10$ We make the following assumption:

Assumption 2. $V_{L}<S^{\min }<V<S^{\max }<V_{H}$.

Under the realization $V_{H}$, the net benefit of war is so high that waging war is optimal, for any feasible trade surplus 11 Conversely, $V_{L}$ corresponds to a situation in which the cost of waging war is prohibitive, due, for example, to a strong international pressure or a failure in the collective action process. We refer to the realizations $V_{H}$ and $V_{L}$ as a war shock and a peace shock, respectively, with associated probabilities $\lambda_{W}$ and $\lambda_{P}$ such that $\lambda_{P}+\lambda_{W}<1$. The intermediate realization, $V$, will be referred to as business as usual (BAU). This state captures the situation in which economic considerations, and in particular the state of the trade surplus, make group A swing for either war or peace.

\section{PERFECT INFORMATION EQUILIBRIUM}

To establish a benchmark, we first consider the case in which group A's type is public knowledge. In this case, war spoils trade but conveys no information. We solve the game backwards, starting from the trade game. Let $n_{J}$ denote the probability that a random member of group $J \in\{A, B\}$ plays cooperatively. The expected payoff of cooperation for agent $i$ in group $\mathrm{A}$ is $\mathcal{P}_{i}+c \times n_{B}+(d-l) \times$ $\left(1-n_{B}\right)$, whereas the safe payoff of defection is $d$. Using the definitions of $z$ and $\mathcal{L}_{i}$ provided above, agent $i$ chooses cooperation if $\mathcal{L}_{i} \leq n_{B} \times z$. Conversely, agent $j$ in group $B$ cooperates if $\mathcal{L}_{j} \leq n_{A} \times z$. Hence, the Nash equilibrium conditional on group A's type, $k \in\{+,-\}$, is given by the fixed point

$$
\left\{n_{A}^{k}, n_{B}^{k}\right\}=\left\{F^{k}\left(z n_{B}^{k}\right), F^{B}\left(z n_{A}^{k}\right)\right\} .
$$

Due to the strategic complementarity, the trade game can feature multiple Nash equilibria. Since the mechanism underlying coordination failures in this environment is well understood (see Cooper and John, 1988), we abstract from it in this article. In particular, Assumption 1 is sufficient to ensure that a unique Nash equilibrium exists under perfect information. This restriction allows us to focus more sharply on the dynamic interaction between belief formation and warfare.

9. A voting process à la Lindbeck and Weibull (1987) would yield the same outcome.

10. The main results of the article can be extended to a model where $\mathcal{V}$ is drawn from a continuous distribution. However, the analysis is more involved. See Rohner et al. (2012).

11. $\mathcal{V}=V_{H}$ can reflect also a temporary explosion of hatred (Gurr, 1970) or the capture of the political process by a biased political elite (Jackson and Morelli, 2007). 
The trade surplus accruing to group A under peace is given by

$$
\begin{aligned}
S^{k} & \equiv n_{A}^{k} \times\left[n_{B}^{k} \times c+\left(1-n_{B}^{k}\right) \times(d-l)\right]+\int_{-\infty}^{z n_{B}^{k}}(l-\mathcal{L}) d F^{k}(\mathcal{L})+\left(1-n_{A}^{k}\right) \times d \\
& =d+z \times\left(n_{A}^{k} \times n_{B}^{k}\right)-\int_{-\infty}^{z n_{B}^{k}} \mathcal{L} d F^{k}(\mathcal{L}) .
\end{aligned}
$$

This expression has a simple interpretation: (i) $d$ is the basic surplus from defection; (ii) $z \times$ $\left(n_{A}^{k} \times n_{B}^{k}\right)$ is the extra surplus generated by mutual cooperation, where $n_{A}^{k} \times n_{B}^{k}$ is the measure of successful trade relationships; (iii) $\int_{-\infty}^{z n_{B}^{k}} \mathcal{L} d F^{k}(\mathcal{L})$ is the total loss (net of aggregate psychological benefit from following the cooperative norm) suffered by cooperators who are matched with defectors.

Proposition 1. Under Assumption $\square$ and perfect information, the Nash Equilibrium of the trade game conditional on peace exists and is unique. Denoting by $k \in\{+,-\}$ group A's type, the equilibrium proportions of cooperators are given by $\left\{n_{A}^{k}, n_{B}^{k}\right\}$ as given by Equation (2) where, $n_{A}^{-} \leq n_{A}^{+}$and $n_{B}^{-} \leq n_{B}^{+}$. The equilibrium trade surplus accruing to group $A$ is $S^{\min }=d+z n_{A}^{-} n_{B}^{-}-$ $\int_{-\infty}^{z n_{B}^{-}} \mathcal{L} d F^{-}(\mathcal{L})$ for the uncivic type and by $S^{\max }=d+z n_{A}^{+} n_{B}^{+}-\int_{-\infty}^{z n_{B}^{+}} \mathcal{L} d F^{+}(\mathcal{L})$ for the civic type, where $S^{\min } \leq S^{\max }$. The probability of war is larger for the uncivic type $\left(1-\lambda_{P}\right)$ than for the civic type $\left(\lambda_{W}\right)$.

Since $S^{\min }<V<S^{\max }$, under BAU the uncivic type wages war while the civic type retains peace. Hence, when group A is civic (uncivic) war occurs with the constant probability $\lambda_{W}$ $\left(1-\lambda_{P}\right)$.

\subsection{Welfare implications}

The Nash equilibrium is generically suboptimal because of two interacting sources of inefficiency. First, conditional on peace, trade cooperation is inefficiently underprovided. This result echoes the analysis of supermodular games with random matching and externalities in Cooper and John (1988). In our model, an increase in the proportion of cooperators in group A (B) has a direct positive externality on group B (A). Moreover, by inducing more agents in group B (A) to cooperate, it has a beneficial feedback effect on group A (B). A "social planner" maximizing the sum of the welfare of the two groups would attain a more efficient outcome by inducing more cooperation. This result holds true irrespective of group A's type 12 Second, war imposes welfare losses on group B (in the form of physical destruction, human lives, etc.) that are not internalized by the unilateral war decision of group $A 13$ If we denote such costs by $V_{B}$, then war is always globally inefficient whenever $\mathcal{V}<\left(S^{k}+S^{B}+V_{B}\right)$, where $S^{B}$ is group B trade surplus. Perhaps more interestingly, the Nash equilibrium may feature too many wars even from the self-regarding

12. More formally, the efficient solution prescribes that $z n_{B}^{k *}\left(1+f^{B}\left(\overline{\mathcal{L}}_{A}^{k}\right)\right)=\overline{\mathcal{L}}_{A}^{k}$ and $z n_{A}^{k *}\left(1+f^{k}\left(\overline{\mathcal{L}}_{B}^{k}\right)\right)=\overline{\mathcal{L}}_{B}^{k}$, where both $n_{A}^{k *}$ and $n_{B}^{k *}$ are larger than in the decentralized equilibrium. In the case of uniform distributions, this yields $n_{A}^{k *}=$ $F^{k}\left(z n_{B}^{k *}\left(1+\bar{f}^{B}\right)\right)>F^{k}\left(z n_{B}^{k}\right)$ and $n_{B}^{k *}=F^{B}\left(z n_{B}^{k *}\left(1+\bar{f}^{k}\right)\right)>F^{B}\left(z n_{A}^{k}\right)$, where $\bar{f}^{k}$ and $\bar{f}^{B}$ are the constant density functions. See Supplementary Appendix $C$ for details.

13. We do not allow for cross-group transfers that could reduce the scope of wars. As usual, such transfers entail commitment problems (cf. Fearon, 1995; Powell, 2006). In the case of ex ante transfers, group A could cash in, and still wage war. In the case of ex post transfers, group B could refuse to pay once the risk of war is gone. 
standpoint of group A, due to the inefficiency in the trade game. Namely, more cooperation could lead group A to retain peace in situations where the Nash equilibrium does prescribe war. In particular, it is easy to construct examples in which the efficient level of cooperation in the trade game would induce both the civic and the uncivic type to preserve peace under BAU, and yet the Nash equilibrium features war when A is uncivic. In other words, the underprovision of cooperation induces a second layer of inefficiency in the form of too frequent wars.

\section{ASYMMETRIC INFORMATION}

From now on in the article, we assume that group B can observe neither group A's type nor the realization of $\mathcal{V}$. In this environment, war and peace become public signals of group A's type. Beliefs are common knowledge, and are updated using Bayes' rule after the observation of war or peace.

We denote by $\pi_{-1} \in[0,1]$ the prior belief held by group B that group A's type is civic (or, less formally, the extent to which group B trusts group A) and by $\pi_{W}$ and $\pi_{P}$, the posterior beliefs conditional on war and peace, respectively. It is often convenient to take the likelihood ratios: $r_{-1} \equiv \pi_{-1} /\left(1-\pi_{-1}\right)$ and $r_{s} \equiv \pi_{s} /\left(1-\pi_{s}\right)$, for $s \in\{W, P\}$. Finally $\left(\sigma^{-}, \sigma^{+}\right)$denote the probability that peace is chosen under BAU by the uncivic and civic type, respectively.

The timing of the game is the following.

1. The war stage: agents in group B receive the common prior belief $r_{-1}$, agents in group A observe the state $\mathcal{V}$. Conditional on its own type, $k \in\{-,+\}$, group A decides to wage war with probability $1-\sigma^{k}$.

2. The trade stage: agents in group B update their beliefs. If there is peace, agents are randomly matched, gains from trade are realized, and consumption occurs.

The equilibrium concept is Perfect Bayesian Equilibria (PBE).

Definition 1. A strategy for an agent in population A specifies for each possible types, $k \in\{+,-\}$ and for each state $\mathcal{V} \in\left\{V_{L}, V, V_{H}\right\}$, conditional on public beliefs, a war action ("wage war" or "keep peace"), and, for each possible realization of the idiosyncratic preference shock, $\mathcal{P}, a$ trade action ("cooperate" or "defect"). A strategy for an agent in population B specifies a trade action ("cooperate" or "defect") for each of the possible realizations of the idiosyncratic preference shock, $\mathcal{P}$, conditional on public beliefs. A PBE is a strategy profile, a belief system and a triplet $\left(n_{A}^{-}, n_{A}^{+}, n_{B}\right) \in[0,1]^{3}$ such that: $(i)$ in the trade continuation game all agents choose their action so as to maximize the expected pay-off conditional on the posterior likelihood ratio of beliefs after peace, $r_{P}$, and the realization of the preference shock $\mathcal{P} ;\left(n_{A}^{-}, n_{A}^{+}, n_{B}\right)$ yields the associated measure of agents who optimally cooperate in group A for each type, $k \in\{+,-\}$, and for group $B$, respectively. (ii) group A chooses the probability $1-\sigma^{k}$ of waging war on group $B$ so as to maximize the total expected utility of its members, given group A's type ( $k)$, the shock $\mathcal{V} \in\left\{V_{L}, V, V_{H}\right\}$ and the prior likelihood ratio of beliefs, $r_{-1}$; (iii) beliefs are updated using Bayes' rule.

\subsection{Trade game}

We solve the PBE backwards, starting from the Nash equilibrium of the trade game under peace. The reaction function of group A, which is fully informed, continues to be given by $n_{A}^{k}=F^{k}\left(z n_{B}\right)$, with $k \in\{+,-\}$. Since $n_{A}$ depends on type $k$ which group B does not observe, group B's reaction function becomes $F^{B}\left(z \mathbb{E}_{B}\left(n_{A} \mid \pi_{P}\right)\right)=F^{B}\left(z\left[\pi_{P} n_{A}^{+}+\left(1-\pi_{P}\right) n_{A}^{-}\right]\right)$. Rescaling the belief $\pi_{P}$ in 
term of its likelihood ratio $r_{P}$, we obtain that the equilibrium proportions of cooperators in the two groups satisfy the following fixed-point equation:

$$
\left\{n_{A}^{-}, n_{A}^{+}, n_{B}\right\}=\left\{F^{-}\left(z n_{B}\right), F^{+}\left(z n_{B}\right), F^{B}\left(\frac{r_{P}}{1+r_{P}} z F^{+}\left(z n_{B}\right)+\frac{1}{1+r_{P}} z F^{-}\left(z n_{B}\right)\right)\right\} .
$$

Proposition 2 characterizes the set of Nash equilibria of the trade game.

Proposition 2. Under Assumption $\square$ and given a likelihood ratio of posterior beliefs $r_{P} \in$ $[0,+\infty)$, the Nash Equilibrium of the trade game conditional on group A's type $k \in\{+,-\}$ exists and is unique. The equilibrium proportions of cooperators are given by $\left\{n_{A}^{-}\left(r_{P}\right), n_{A}^{+}\left(r_{P}\right), n_{B}\left(r_{P}\right)\right\}$, implicitly defined by Equation (4). $n_{A}^{-}\left(r_{P}\right), n_{A}^{+}\left(r_{P}\right)$ and $n_{B}\left(r_{P}\right)$ are continuous, weakly increasing and lie strictly within the unit interval. Moreover, $n_{A}^{-}\left(r_{P}\right) \leq n_{A}^{+}\left(r_{P}\right)$.

The equilibrium trade surplus accruing to group $A, S^{k}\left(r_{P}\right)$, is given by

$$
S^{k}\left(r_{P}\right) \equiv d+z n_{A}^{k}\left(r_{P}\right) n_{B}\left(r_{P}\right)-\int_{-\infty}^{z n_{B}\left(r_{P}\right)} \mathcal{L} d F^{k}=d+\int_{-\infty}^{z n_{B}\left(r_{P}\right)} F^{k}(\mathcal{L}) d \mathcal{L} .
$$

$S^{k}\left(r_{P}\right)$ is weakly increasing in $r_{P}$. Moreover, $S^{-}\left(r_{P}\right) \leq S^{+}\left(r_{P}\right)$.

Proposition 2 shows that trust has a social value: optimistic prior beliefs about group A's type (large $r_{P}$ ) induce more cooperative behaviour from both groups (large $n_{A}$ and $n_{B}$ ), and a larger trade surplus, due to the strategic complementarity: the trust in group A makes group B more cooperative; this in turn makes group B more trustworthy in group A's eyes, further enhancing the cooperation of group A, and so on. To the opposite, a vicious circle of low trust and trustworthiness makes cooperation unravel, reducing the trade surplus. Figure1 1 plots the equilibrium trade surplus (conditional on group A's actual type) against the posterior belief, $\pi_{P}=r_{P} /\left(1+r_{P}\right)$, in the case of a uniform distribution of $\mathcal{P} 14$

\subsection{War decision and PBE}

In this subsection, we analyse the group A's war decision, based on the comparison between the trade surplus, $S^{k}\left(r_{P}\right)$, and the realization of the stochastic benefit of war, $\mathcal{V}$. Since the trade surplus depends on posterior beliefs, we must characterize the mapping from prior to posterior. Bayes' rule yields

$$
\begin{aligned}
& \ln r_{P}\left(r_{-1}\right)=\ln r_{-1}+\ln \frac{\lambda_{P}+\left(1-\lambda_{W}-\lambda_{P}\right) \sigma^{+}\left(r_{-1}\right)}{\lambda_{P}+\left(1-\lambda_{W}-\lambda_{P}\right) \sigma^{-}\left(r_{-1}\right)}, \\
& \ln r_{W}\left(r_{-1}\right)=\ln r_{-1}-\ln \frac{1-\lambda_{P}-\left(1-\lambda_{W}-\lambda_{P}\right) \sigma^{-}\left(r_{-1}\right)}{1-\lambda_{P}-\left(1-\lambda_{W}-\lambda_{P}\right) \sigma^{+}\left(r_{-1}\right)},
\end{aligned}
$$

where the optimal choice of maintaining peace is given by

$$
\sigma^{k}\left(r_{-1}\right)=\left\{\begin{array}{cl}
0 & \text { if } S^{k}\left(r_{P}\left(r_{-1}\right)\right)<V \\
\in[0,1] & \text { if } S^{k}\left(r_{P}\left(r_{-1}\right)\right)=V \\
1 & \text { if } S^{k}\left(r_{P}\left(r_{-1}\right)\right)>V
\end{array}\right.
$$

14. We set $z=0.9, d=0$, and assume $F^{B} \sim[0,1], F^{+} \sim[-0.25,1], F^{-} \sim[0,1.25]$. The geometric representation entails some slight abuse of notation, as $S^{k}$ was defined to be a function of the likelihood ratio $r_{P}$ rather than of $\pi_{P}$. We prefer this representation since $\pi_{P} \in[0,1]$, and we can display the range of variation of the surplus for any belief. 


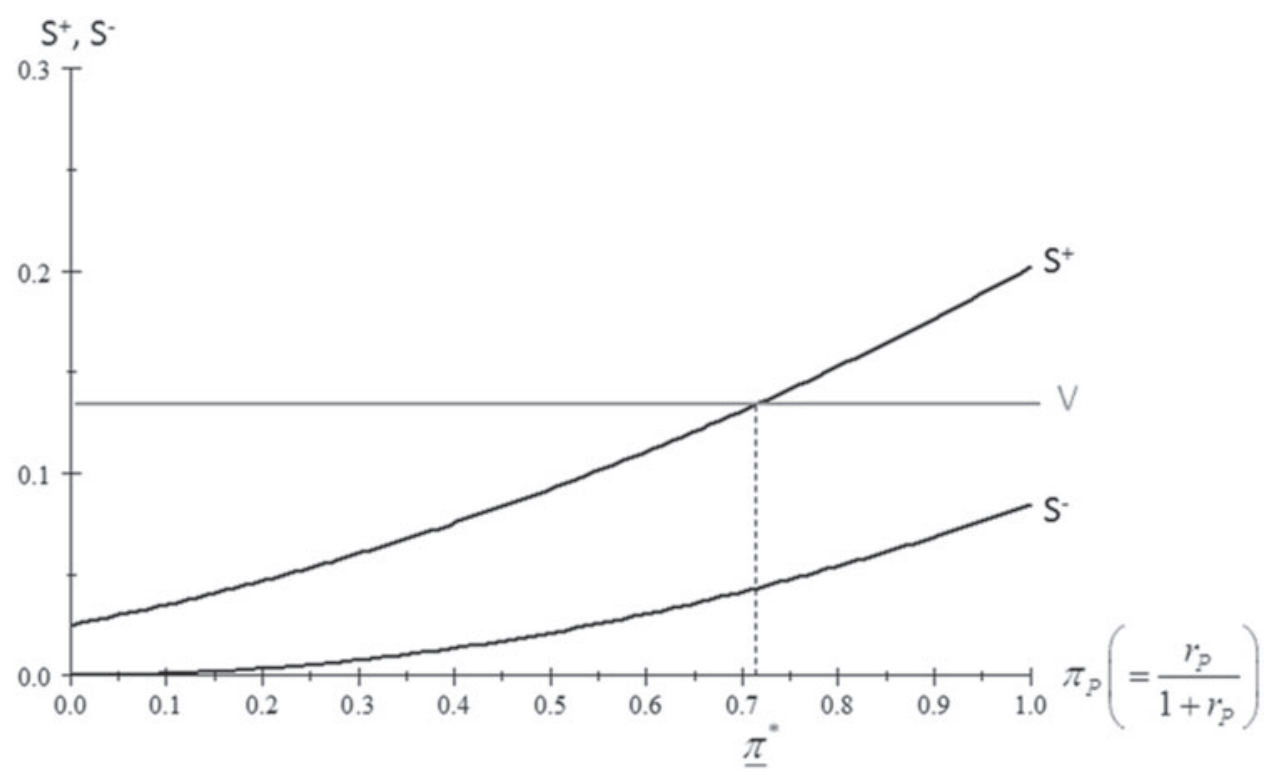

FIGURE 1

Surplus from trade as function of the posterior belief, and war benefit under BAU

Note that, since $S^{k}$ depends on $r_{P}$, which is endogenous to the war/peace decision, the characterization of the optimal choice of $\sigma^{k}$ involves a fixed-point problem that can yield multiple solutions.

Proposition 3 establishes the existence of the PBE. The proof follows immediately from Proposition 2 and is omitted.

Proposition 3. A PBE exists and is fully characterized by the set of Equations (4), (5), (6), (7), (8), given a likelihood ratio of prior beliefs $r_{-1} \in[0,+\infty)$.

The posterior belief is independent of the observation of war or peace whenever $\sigma^{+}=\sigma^{-}$. This may happen when priors are either very optimistic or, to the opposite, very pessimistic. In particular, if $V<S^{-}\left(r_{P}\right)$, then both types retain peace under BAU $\left(\sigma^{+}\left(r_{-1}\right)=\sigma^{-}\left(r_{-1}\right)=1\right)$, whereas if $V>S^{+}\left(r_{P}\right)$, then both types wage war under BAU $\left(\sigma^{+}\left(r_{-1}\right)=\sigma^{-}\left(r_{-1}\right)=0\right)$. On the contrary, the observation of war or peace is informative whenever $S^{-}\left(r_{P}\right) \leq V \leq S^{+}\left(r_{P}\right)$ - with one inequality being strict. In this case, the uncivic type would wage war whereas the civic type would preserve peace $\left(\sigma^{+}\left(r_{-1}\right)=1\right.$ and $\left.\sigma^{-}\left(r_{-1}\right)=0\right)$. Thus, peace strengthens the trust of group B towards group A, while war undermines it. More formally, $S^{-}\left(r_{P}\right) \leq V \leq S^{+}\left(r_{P}\right) \Leftrightarrow r_{P}>r_{-1}>$ $r_{W}$. We refer to this situation as an informative PBE.

Definition 2. Given $r_{-1}$ a PBE is "informative" iff $\sigma^{+}\left(r_{-1}\right)>\sigma^{-}\left(r_{-1}\right)$, or identically iff $r_{P}\left(r_{-1}\right)>r_{-1}>r_{W}\left(r_{-1}\right)$. A PBE is "uninformative" iff $\sigma^{+}\left(r_{-1}\right)=\sigma^{-}\left(r_{-1}\right)$, or identically iff $r_{P}\left(r_{-1}\right)=r_{-1}=r_{W}\left(r_{-1}\right)$.

Throughout the rest of the article, we maintain that $V>S^{+}(0)$. This restriction sharpens the focus on the more interesting case, in which pessimistic beliefs can induce even the civic type to wage war. For expositional purposes, it is convenient to consider two cases separately: high 
value of war $\left(S^{-}(\infty)<V<S^{+}(\infty)\right)$ and low value of war $\left(V \leq S^{-}(\infty)<S^{+}(\infty)\right) 15$ High value of war will be our main case, since it delivers the main economic insights in a simpler way. In this case, the uncivic type always wages war under BAU, irrespective of public beliefs. The case of low value of war, where the uncivic type may find it optimal to mimic the civic type by maintaining peace under BAU, is discussed in Supplementary Appendix B. Figure 1 represents the case of high value of war: $S^{-}<V$ for all $\pi_{P}$, and there exists $\underline{\pi}^{*}$ such that $S^{+}>V$ if $\pi_{P}>\underline{\pi}^{*}$ and $S^{+}<V$ if $\pi_{P}<\pi^{*}$.

We now discuss the equilibrium mapping from prior to posterior.

Lemma 1. Assume $V>S^{+}(0)$ and $S^{-}(\infty)<V<S^{+}(\infty)$. Let $\underline{r}^{*}$ be such that $V=S^{+}\left(\underline{r}^{*}\right)$, and let $\underline{r} \equiv \lambda_{P} \underline{r}^{*} /\left(1-\lambda_{W}\right)$. For $r_{-1} \leq \underline{r}$ the $P B E$ is unique and uninformative. For $r_{-1} \in\left[\underline{r}, \underline{r}^{*}\right]$ there are multiple PBE. For $r_{-1}>\underline{r}^{*}$ the PBE is unique and informative.

$\underline{r}^{*} \equiv \underline{\pi}^{*} /\left(1-\underline{\pi}^{*}\right)$ is the threshold posterior likelihood ratio below which both types wage war under BAU. Uninformative PBE are associated with pessimistic priors. Intuitively, when trust is low, trade opportunities are scant and both the civic and the uncivic type wage war under BAU. When $r_{-1} \in\left[\underline{r}, \underline{r}^{*}\right]$, the mapping [8] yields multiple PBE: one uninformative and two informative ones (one of which involves mixed strategies). While none of our results depends on a specific selection criterion, we make the following convenient assumption.

Assumption 3. In the range of prior beliefs such that multiple PBE exist, the most informative equilibrium is selected.

Since our analysis emphasizes the possibility that economies fall into uninformative equilibria, this is the most conservative selection criterion.

In summary, this section has established the existence and characterization of the set of PBE (Proposition 3). It has, in addition, introduced a formal distinction between informative and uninformative PBE and established that for a pessimistic prior the PBE is unique and uninformative, while for an optimistic prior the PBE is unique and informative, and for a range of intermediate beliefs there are multiple equilibria (Lemma 11. For this latter case, we provide a simple selection criterion that simplifies the analysis of the dynamic model.

\section{THE DYNAMIC MODEL}

In this section, we extend the analysis to a dynamic economy populated by non-altruistic overlapping generations of two-period lived agents. The purpose here is to characterize the endogenous intertemporal link between stochastic wars and beliefs, which is the main contribution of this article. In the first period of their lives agents make no economic choice, and acquire a common prior belief, based on the public history regarding warfare 16 In the second period agents make all economic decisions. After group A decides whether or not to wage war, agents in group $\mathrm{B}$ update their beliefs. In the case of peace, agents are randomly matched to trade. We assume that the information set of young agents comprises only the history of warfare. In particular, we rule out that young agents can observe the success of inter-ethnic trade during peace 17

15. In the case of low value of war, we assume also that $S^{+}(0)<S^{-}(\infty)$. The set of parameters for which this inequality holds is non-empty.

16. Since young agents are passive and earn no pay-off, one could interpret the model alternatively in terms of a sequence of one-period lived agents.

17. If agents in group B could observe the average success of current inter-ethnic trade, they could attain a perfect inference of group A's type. Information about the success of inter-community trade in reality is sparse, and difficult 
The dynamics of beliefs drives the stochastic process of war, peace, and trade. We denote by $r_{0}$ the common prior of the adult generation at time zero.

Definition 3. A Dynamic Stochastic Equilibrium (DSE) is a sequence of PBE with an associated sequence of beliefs such that, given an initial likelihood ratio $r_{0}$, the posterior likelihood ratio at $t-1$ is the prior likelihood ratio at $t$, for all $t \geq 0$.

Combining Equations [6-8), Lemma 1 and Assumption 3 the equilibrium law of motion of the likelihood ratio of beliefs is given by the following stochastic difference equation:

$$
\ln r_{t}= \begin{cases}\ln r_{t-1} & \text { if } r_{t-1} \in[0, \underline{r}] \\ \ln r_{t-1}+\left(1-\mathbb{W}_{t}\right) \ln \left(\frac{1-\lambda_{W}}{\lambda_{P}}\right)-\mathbb{W}_{t} \ln \left(\frac{1-\lambda_{P}}{\lambda_{W}}\right) & \text { if } \quad r_{t-1}>\underline{r}\end{cases}
$$

where $\mathbb{W}_{t} \in\{0,1\}$ is a random variable taking on the unit (zero) value if there is war (peace) at date $t$. Also, recall that $1>\lambda_{W}+\lambda_{P}$. In the low-trust region, $r_{t-1} \in[0, \underline{r}]$, the probability of peace is low $\left(\mathbb{P}\left(\mathbb{W}_{t}=0\right)=\lambda_{P}\right)$ and beliefs are stationary irrespective of group A's type. The observation of a peace event is attributed rationally to a peace shock. In contrast, in the hightrust region, $r_{t-1}>\underline{r}$, the probability of peace is low $\left(\mathbb{P}\left(\mathbb{W}_{t}=0\right)=\lambda_{P}\right)$ if $\mathrm{A}$ is uncivic, and high $\left(\mathbb{P}\left(\mathbb{W}_{t}=0\right)=1-\lambda_{W}\right)$ if $\mathrm{A}$ is civic. In addition, the equilibrium is informative and peace leadsthrough Bayesian updating - to an increase in the belief that group A is civic. The stochastic process 9 is represented in Figure 2 which is zoomed around the threshold $\underline{r}$.

Suppose that group A is civic, implying that peace and high cooperation would prevail under perfect information (Proposition 11. Under imperfect information, this low-conflict outcome is an equilibrium only if trust is sufficiently high, $r_{t}>\underline{r}$. Moreover, an unlucky sequence of war shocks can spoil trust forever. As soon as $r_{t}$ crosses (from above) the threshold $\underline{r}$, group A starts waging war under BAU even though it is civic, and the probability of war jumps from $\lambda_{W}$ to $1-\lambda P$. Group B rationally stops updating its beliefs, and no peace spell-no matter how long-can restore trust. The following proposition summarizes the formal characterization of the dynamic equilibrium (proof in the text).

Proposition 4. Assume that $V>S^{+}(0)$ and $S^{-}(\infty)<V<S^{+}(\infty)$. Then, the DSE is characterized by Proposition 3 and by the law of motion (9). If group $A$ is uncivic, the probability of war is $\mathbb{P}\left(\mathbb{W}_{t}=1\right)=1-\lambda_{P}$. If group $A$ is civic, the probability of war is $\mathbb{P}\left(\mathbb{W}_{t}=1\right)=1-\lambda_{P}$ if $r_{t-1}<\underline{r}$, and $\mathbb{P}\left(\mathbb{W}_{t}=1\right)=\lambda_{W}$ if $r_{t-1} \geq \underline{r}$.

\subsection{War traps and long-run distribution}

The next step is to characterize the long-run equilibrium outcome. We start by defining a war trap.

Definition 4. A "war trap" is a set of states, $\Omega_{T R A P} \subset \mathbb{R}^{+}$, such that, for all $r_{t} \in \Omega_{T R A P}$, group A strictly prefers war under BAU irrespective of its type, and beliefs are stationary: $\forall s \geq t, r_{s}=r_{t}$.

to collect or to distinguish from intra-ethnic trade. In the benchmark model discussed in this section, we also rule out that young agents can observe private signals (e.g. a finite sample of trade outcomes). Otherwise, agents would enter the second period of their lives with heterogenous beliefs, and the dynamic model would become intractable. We relax this assumption in Section 6.2 where we assume that cohorts are connected through dynastic links, and allow information acquired by traders to be transmitted within families. 


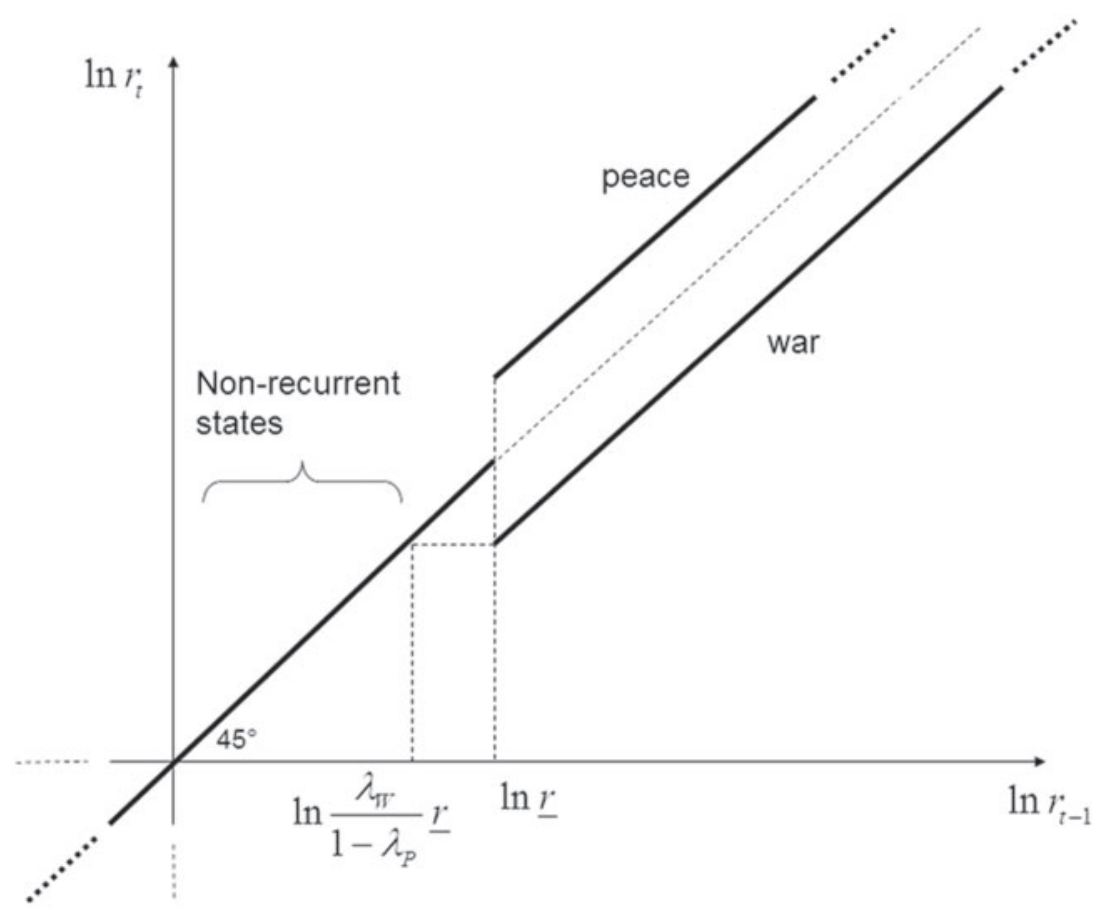

FIGURE 2

Stochastic law of motion of beliefs

It follows immediately from (9) that $\Omega_{T R A P}=[0, \underline{r})$. Whatever the state of beliefs, $r_{t}<\infty$, the economy falls into the war trap with a positive probability, since a finite number of war shocks can plunge trust below the threshold $\underline{r}$. Once the economy is in the trap, beliefs are stationary, trade is scant, and war is frequent. Note that both war and peace shocks are essential for a war trap to exist. If only war shocks existed, peace would become a perfectly revealing signal since, contrary to the civic type, the uncivic type would never retain peace under BAU. Thus, the civic type could reveal his type by not waging war under BAU, and the equilibrium would be identical to the case of perfect information.

Since the dynamics have no rest point in the informative equilibrium region, one might wonder whether the economy is deemed to fall into the war trap in the long run. The answer to this question depends on whether group $\mathrm{A}$ is civic or uncivic.

Proposition 5. Assume that $V>S^{+}(0), S^{-}(\infty)<V<S^{+}(\infty)$, and $r_{0}>\underline{r}$.

(i) If group $A$ is uncivic, then the DSE enters the war trap in finite time with probability one.

(ii) If group A is civic, then the DSE enters the war trap in finite time with probability $\mathbb{P}_{\text {TRAP }}>0$, and stays out of the war trap forever with probability $1-\mathbb{P}_{\text {TRAP }}>0$. If the economy stays out of the trap, the DSE converges to perfect learning, i.e. $r_{t} \rightarrow \infty$, and war incidence stays permanently low, $\mathbb{P}\left(\mathbb{W}_{t}=1\right) \longrightarrow \lambda_{W}$.

(iii) The probability $\mathbb{P}_{\text {TRAP }}$ has the following bounds:

$$
0<\frac{\lambda_{W}}{1-\lambda_{P}} \frac{\underline{r}}{r_{0}}<\mathbb{P}_{T R A P} \leq \frac{\underline{r}}{r_{0}}<1 .
$$


If group A is civic, the economy averts the trap in the long run with a positive probability. However, if group A is uncivic, the war trap is attained almost surely. The proof is based on the Martingale Convergence Theorem, ensuring that the stochastic belief $\pi_{t}$ converges almost surely to a limit. This limit—as the proof shows - cannot lie in the interior of the informative region, thus either $\pi_{t}$ enters the trap or $\lim _{t \rightarrow \infty} \pi_{t}=1$. In order for $\lim _{t \rightarrow \infty} \pi_{t}=1$, the economy must remain forever in the informative region. This possibility can be ruled out if group A is uncivic, since the Strong Law of Large Numbers would then imply that group B could observe an infinite sample of realizations of the war/peace process, and eventually learn the truth, i.e. that group A is uncivic. This would cause a contradiction. On the contrary, when group A is civic, group B can learn asymptotically the truth (i.e. $\lim _{t \rightarrow \infty} \pi_{t}=1$ ) with positive probability. However, this is not the sole possible outcome. Alternatively, the economy can fall into the war trap with positive probability. So, the long-run fate of the economy hinges on luck, or the realization of the stochastic process of peace/war (similarly to Acemoglu and Zilibotti, 1997) 18 Proposition 5 establishes a lower and an upper bound to the probability that the economy falls into the trap. However, in a particular case, we can obtain an exact characterization of $\mathbb{P}_{T R A P}$ :

Corollary 1. Assume that group A is civic, $V>S^{+}(0), S^{-}(\infty)<V<S^{+}(\infty), \lambda_{W}=\lambda_{P}=\lambda$ and $r_{0}>\underline{r}$. Then, the probability that the economy falls into the war trap is $\mathbb{P}_{T R A P}=\left(\frac{\lambda}{1-\lambda}\right)^{\Delta\left(r_{0}\right)}$, where $\Delta\left(r_{0}\right) \equiv\left\lceil\left(\ln r_{0}-\ln \underline{r}\right) /(\ln (1-\lambda)-\ln \lambda)\right\rceil$.

Note that $\Delta\left(r_{0}\right)$ counts the number of war episodes minus that of peace episodes which is necessary in order for $r$ to cross the threshold $\underline{r}$, given the initial belief $r_{0}$. Intuitively, $\mathbb{P}_{T R A P}$ decreases with $r_{0}$. Thus, the probability of an economy falling into a war trap increases (falls) after each war (peace) episode, since this reduces (increases) $r$. Our theory predicts, then, that war is endogenously persistent: each conflict increases the probability of future conflicts.

When group A is civic, war traps are inefficient outcomes, even relative to the second-best implemented under perfect information (where, recall, peace is retained under BAU). There are too many wars and, in addition, there is less cooperation than under perfect information. When the economy converges to perfect learning, the equilibrium is asymptotically identical to the perfect information outcome, although there is inefficiency along transition. Conversely, when A is uncivic, war traps may yield higher welfare than the perfect information equilibrium. In the trap, group B fails to learn perfectly about the uncivicness of group A. Consequently, peace spells are characterized by more economic cooperation than under perfect information. Since cooperation tends to be suboptimally low (see Section 3.1), imperfect learning in this case can improve the welfare of both groups.

\subsection{War traps and related literature}

In our model, the key for the existence of war traps is that, in some range of priors, the equilibrium has a separating nature (i.e. different types take different actions-waging war or retaining peace), whereas for another range of priors the equilibrium has a pooling nature. In a pooling equilibrium there is no informative public signal. The dynamics can push the equilibrium towards the pooling low-trust equilibrium, even though group A is civic. The reason is that, although beliefs are

18. The war decision entails an intergenerational spillover, as war depletes trust and harms future generations. In Supplementary Appendix B, we show that an equilibrium isomorphic to that of Propositions 4 and 5 can be sustained as the Markov Perfect Equilibrium of an extended model where the decision to stage war incorporates an altruistic concern towards the next generation. 
updated rationally, the updating process is subject to disturbances over time. Signal jamming due to war and peace shocks makes it possible that agents update beliefs "in the wrong direction". While a long enough further sampling eventually would correct temporary mistakes and lead to correct learning, sampling de facto ends (in the sense that agents stop receiving informative signals) as soon as the economy enters the pooling equilibrium region.

While learning traps are not per se a novel finding, their source and mechanism here are different from those described in the existing literature, to the best of our knowledge. In models of informational cascades (see, e.g. Bikhchandani et al., 1992), agents make decisions sequentially, having access to private information and a public signal. They may end up in an informational cascade where each agent rationally ignores her private information and conforms to the behaviour of the majority. In contrast, in our model there is no private information. In Piketty (1995), learning traps are driven by costly experimentation and imperfect common knowledge. In his paper, people with identical preferences, but different sampling histories, may end up having persistently heterogeneous beliefs about the cost of redistribution. The mechanism is again very different from ours, where all information is public. Experimentation is key also in Aghion et al. (2011). Chamley (1999) studies coordination and social learning in a dynamic setting with uncertainty and strategic complementarities. The environment is different from ours insofar as the game features multiple equilibria under perfect information, whereas in our stag hunt game the equilibrium is always unique. The main difference in the social learning process is that in his model the dynamics are driven by exogenous changes in unobservable fundamentals, while in our model the dynamics depend on the individual decisions of players that determine the surplus from trade. While in our setting learning can break down fully, this is never the case in Chamley's model. In the extension of Section 6.1 we move closer to Chamley's setting by studying the possibility that group A's type changes stochastically.

\subsection{War persistence}

Our analysis is motivated by the evidence that civil wars feature hysteresis, namely, a conflict today increases the probability of future conflicts (see Section 1.1. In the model presented above, each war episode increases smoothly the long-term frequency of conflicts 19 Similarly, one can compute the effect of a war at $t$ on the probability of conflict at $t+T$, for $\infty>T \geq 1$ (as long as group A is civic). For each lead $T$, there exists a threshold $\underline{r}_{T} \equiv \underline{r} \times\left(\frac{1-\lambda_{P}}{\lambda_{W}}\right)^{T}$ such that, for all $\left.r_{t} \in\right] \underline{r}, \underline{r}_{T}$ [, a war at $t$ increases the probability of war at $t+T$. The nature of the persistence becomes somewhat stark if one looks at the short-run dynamics $(T=1)$ : then, the probability of war at $t+1$ increases discretely after a war at $t$ only if $r_{t}$ is in a right-hand neighbourhood of $\underline{r}$ such that the war immediately pushes the economy into the trap. This is not a robust feature of the theory. Rather, it hinges on the simplifying assumption that the stochastic process $\mathcal{V}$ has a discrete support. If one assumes that $\mathcal{V}$ is drawn from a continuous distribution, the theory predicts a smoother form of short-run persistence.

In this section, we sketch the argument for the case of a particular continuous distribution of $\mathcal{V} 20$ Suppose $\mathcal{V}$ is distributed uniformly in the interval $\left[V_{L}, V_{H}\right]$ where $V_{L}<S^{-}(0)$

19. If we define the long run frequency of conflicts (when group $\mathrm{A}$ is civic) as $\mathbb{F}\left(r_{t}\right) \equiv$ $\lim _{T \rightarrow+\infty} \mathbb{E}\left[\frac{1}{T-t} \sum_{s=t+1}^{T} \mathbb{W}_{s} \mid k=+, r_{t}\right]$, then Proposition 5 (replacing $r_{0}$ by $\left.r_{t}\right)$ implies that $\mathbb{F}\left(r_{t}\right)=\mathbb{P}_{T R A P}\left(r_{t}\right) \times(1-$ $\left.\lambda_{P}\right)+\left[1-\mathbb{P}_{\text {TRAP }}\left(r_{t}\right)\right] \times \lambda_{W}$. Clearly, $\mathbb{F}\left(r_{t}\right)$ is decreasing in $r_{t}$, and each war (peace) episode, by decreasing (increasing) $r_{t}$, increases (reduces) the frequency of future conflict.

20. See Rohner et al. (2012) for a more detailed and formal analysis of the continuous case. There, we also show that war traps carry over to a version of the model with a generic continuous distribution of $\mathcal{V}$. 
$<S^{+}(\infty)<V_{H}$. Note that the range of realizations $\mathcal{V}>S^{+}(\infty)$ and $\mathcal{V}<S^{-}(0)$ can be interpreted as war and peace shocks, respectively. Bayes' rule implies that

$$
\begin{aligned}
& r_{P}\left(r_{t}\right)=\frac{\mathbb{P}\left[\mathcal{V}<S^{+}\left(r_{P}\left(r_{t}\right)\right)\right]}{\mathbb{P}\left[\mathcal{V}<S^{-}\left(r_{P}\left(r_{t}\right)\right)\right]} \times r_{t}=\frac{S^{+}\left(r_{P}\left(r_{t}\right)\right)-V_{L}}{S^{-}\left(r_{P}\left(r_{t}\right)\right)-V_{L}} \times r_{t}>r_{t}, \\
& r_{W}\left(r_{t}\right)=\frac{\mathbb{P}\left[\mathcal{V}>S^{+}\left(r_{P}\left(r_{t}\right)\right)\right]}{\mathbb{P}\left[\mathcal{V}>S^{-}\left(r_{P}\left(r_{t}\right)\right)\right]} \times r_{t}=\frac{V_{H}-S^{+}\left(r_{P}\left(r_{t}\right)\right)}{V_{H}-S^{-}\left(r_{P}\left(r_{t}\right)\right)} \times r_{t}<r_{t} .
\end{aligned}
$$

As in the benchmark model, war (peace) causes a fall (increase) in $r_{t}$. In Rohner et al. (2012) we prove that (i) for any $r_{t}$, there exists a unique PBE; (ii) the gap between $S^{+}$and $S^{-}$increases with $r_{t}$, implying that the war/peace signal becomes more informative as $r_{t}$ grows. The result that the speed of learning increases smoothly with the level of trust is a generalization of the result in the benchmark model above, that the speed of learning stays constant in the informative region $\left(r_{t} \geq \underline{r}\right)$ and falls discretely to zero in the learning trap $\left(r_{t}<\underline{r}\right)$. The endogenous probability of war becomes now a continuous decreasing function of $r_{t}$, rather than a decreasing step function. More formally,

$$
\mathbb{P}\left[\mathbb{W}_{t+1}=1 \mid k, r_{t}\right]=1-\mathbb{P}\left[\mathcal{V}<S^{k}\left(r_{P}\left(r_{t}\right)\right)\right]=\frac{V_{H}-S^{k}\left(r_{P}\left(r_{t}\right)\right)}{V_{H}-V_{L}} .
$$

This is a (continuous) generalization of the second part of Proposition 4 A corollary of 13 is that, for any $r_{t}$, a civil conflict today-by reducing $r_{t}$-increases strictly the probability of a conflict next period. In conclusion, war persistence is a hard prediction of our theory. The particular form that the hysteresis takes in the benchmark model is instead driven by the simplifying assumption that $\mathcal{V}$ has a discrete support.

\section{EXTENSIONS}

In this section, we discuss some important extensions of the benchmark model.

\subsection{Stochastic types}

So far, group A's type was assumed to be a permanent characteristic. In this section, we generalize the analysis to an environment in which the group type is subject to stochastic shocks, driven, for instance, by cultural shifts. For instance, ancient Vikings were an aggressive population prone to war and looting, whereas their current Scandinavian descendants are regarded as peaceful and cooperative people. Cultural shifts in types can be related to low-frequency changes in political regimes, institutions, social structures, or population mixture (see Tabellini 2008).

We assume that group A's type follows a two-state first-order stochastic Markov process with the transition matrix

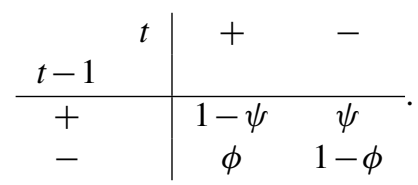

We make the realistic assumption that $\phi \leq 1 / 2$ and $\psi \leq 1 / 2$, implying a positive serial autocorrelation. The ergodic distribution is summarized by the unconditional likelihood ratio that $\mathrm{A}$ is civic $\hat{r}=\phi / \psi$. 
Without loss of generality, we assume that the type shock is realized between the end of period $t-1$ and the beginning of period $t$. This implies that the posterior belief at $t-1$ is no longer identical to the prior belief at $t$. In particular, the mapping from posterior at $t-1$ to prior at $t$ is given by:

$$
\tilde{r}\left(r_{t-1}\right)=\frac{(1-\psi) r_{t-1}+\phi}{\psi r_{t-1}+1-\phi}
$$

where $\tilde{r}^{\prime}\left(r_{t-1}\right)>0$ and $\tilde{r}^{\prime \prime}\left(r_{t-1}\right)<0$. The equilibrium law of motion of beliefs, 9), can be generalized according to the following stochastic difference equation:

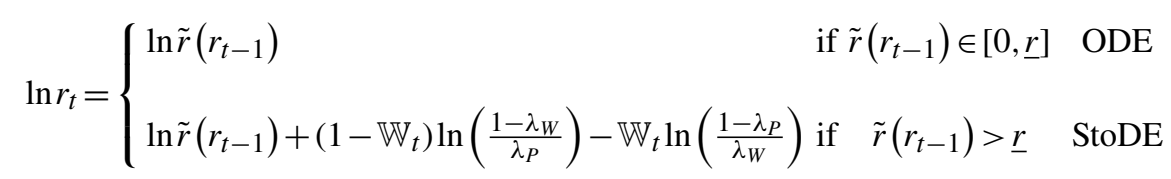

In the uninformative region, $\tilde{r}\left(r_{t-1}\right) \in[0, \underline{r}]$, group A wages war under BAU irrespective of its type, and thus the observation of war/peace conveys no information. The dynamics of beliefs is governed by an ordinary difference equation (ODE) such that $\ln r$ converges to the unconditional $\log$-likelihood ratio, $\ln \hat{r}$. In the informative region, $\tilde{r}\left(r_{t-1}\right)>\underline{r}$, group A wages war when it is uncivic and retains peace when it is civic, under BAU. Thus, the dynamics is governed by a stochastic difference equation (StoDE) comprising both stages of the Bayesian updating: the type shock and war/peace.

A qualitative description of the belief dynamics, 16, is provided by Figure $3{ }^{21}$ It is useful to define two constants:

$$
\hat{r}^{+}=\frac{1-\lambda_{W}}{\lambda_{P}} \times \tilde{r}\left(\hat{r}^{+}\right) \quad \text { and } \quad \hat{r}^{-}=\frac{\lambda_{W}}{1-\lambda_{P}} \times \tilde{r}\left(\hat{r}^{-}\right),
$$

denoting the limits to which the dynamics of beliefs 16 would converge after an infinite sequence of war and peace episodes, respectively, if the realization of war and peace were informative everywhere (i.e. if the dynamics were governed by the StoDE for all $r_{t-1}$ ). Note that $0<\hat{r}^{-}<$ $\hat{r}=\phi / \psi<\hat{r}^{+}$. Three cases are possible (see Supplementary Appendix C for analytical details and proofs):

1. If $\underline{r}>\hat{r}$ (panel a of Figure 3), beliefs converge with probability one to the war trap. Conditional on trust being initially high, the dynamics is governed by the StoDE part of 16 with frequent spells of peace. However, cooperation is deemed to collapse. As soon as $r$ enters the uninformative region, $[0, \underline{r}]$, the ODE of $[16$ drives the belief process to a monotonic convergence to $\hat{r}$. Since $\hat{r}<\underline{r}, \hat{r}$ is an absorbing state. Intuitively, the long-run frequency of the civic type is very low, making peace and cooperation fragile.

2. If $\underline{r} \in\left[\hat{r}^{-}, \hat{r}\right]$ (panel $\mathrm{b}$ of Figure 3), the economy cycles between periods of low trust with frequent wars (uninformative PBE) and periods of peace with thriving trade (informative PBE). Since the dynamics has no rest point-in particular, $\hat{r}$ is not a steady state, as the figure shows- the economy wanders indefinitely in the ergodic set, $\left[\hat{r}^{-}, \hat{r}^{+}\right]$, which comprises portions of both the informative and uninformative region. Suppose that $r_{0}<\underline{r}$. Then, the PBE starts uninformative, and the dynamics is governed initially by the ODE

21. Note that the figure plots likelihood ratios rather than their logarithms, since the graphical representation is more effective in levels than in logs. 


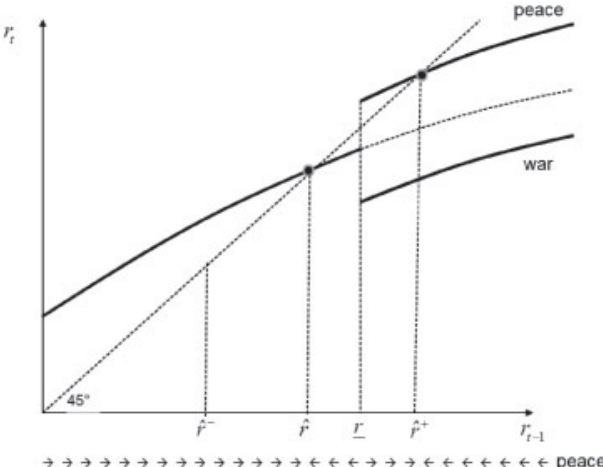

$\rightarrow \rightarrow \rightarrow \rightarrow \rightarrow \rightarrow \rightarrow \rightarrow \rightarrow \rightarrow \rightarrow \rightarrow \rightarrow t+t+t+t+t+t+$ war

Panel a: $\underline{r}>\hat{r}$. The economy converges in the long run to $\hat{r}<\underline{r}$ (war trap).
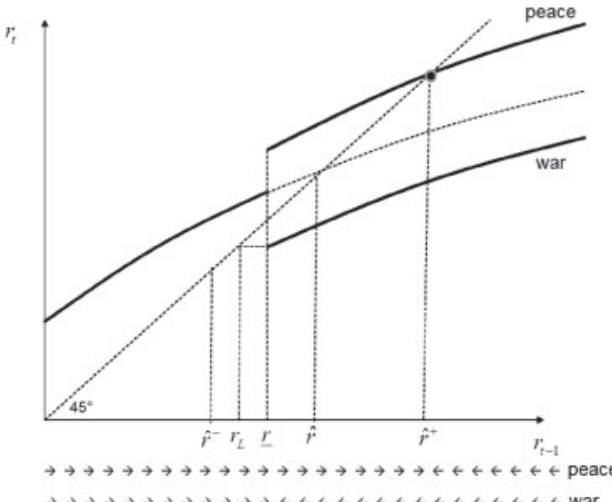

Panel $\mathbf{b}: \underline{r} \in\left[\hat{r}^{-}, \hat{r}\right]$. The economy cycles in the long run in the region $\left[r_{L}, \hat{r}^{+}\right]$, including both informative and uninformative PBE.
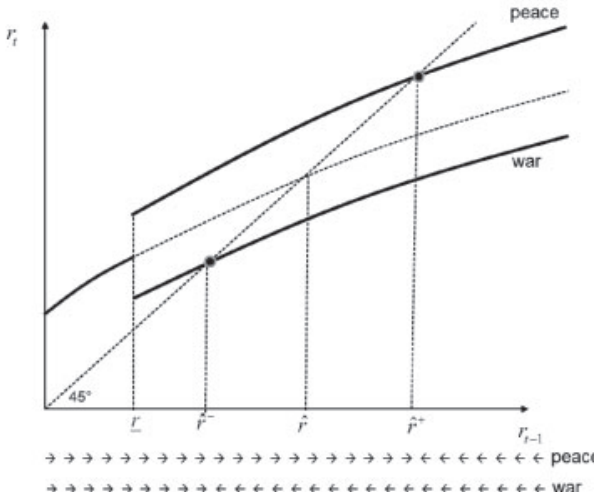

Panel c : $\underline{r}<\hat{r}^{-}$. The economy cycles in the long run in the region $\left[\hat{r}^{-}, \hat{r}^{+}\right]$, where the equilibrium is informative (no war trap).

FIGURE 3

Dynamics of beliefs with stochastic types 
part of (16): $r_{t}$ grows slowly until it crosses the threshold $\underline{r} 22$ Thereafter, the dynamics is governed by the StoDE part of 16]; the PBE remains informative until the stochastic sequence brings $r$ back below the threshold $\underline{r}$. Although the economy does not get stuck into the uninformative equilibrium region, now and then it falls into times of raging conflict.

3. If $\underline{r}<\hat{r}^{-}$(panel c of Figure 3), the uninformative region is never visited in the long run. The ergodic set is again the interval $\left[\hat{r}^{-}, \hat{r}^{+}\right]$, but this lies entirely within the informative region. As soon as the informative region is reached, it is never left, nor do beliefs ever settle to a rest point.

In summary, allowing for shifts in group A's type yields richer dynamics without altering the main insights of our analysis. If the unconditional probability that A is civic is low (panel a of Figure 3 the economy necessarily falls into a war trap. For an intermediate range of parameters (panel b of Figure 3), cycles emerge in which periods of recurrent conflicts and periods of peace and trade alternate. Spells of recurrent wars are preceded by decreases in reciprocal trust. Finally, if the unconditional probability that group A is civic is sufficiently high (panel c of Figure 3), recurrent wars are not observed in the long run. This case may represent well-functioning developed societies for which conflicts are rare.

Structural factors such as weak institutions, low human capital, or abundance of natural resources can determine which of the three regimes prevails. However, these factors alone would not fully explain the dynamics of conflict. In particular, in the intermediate regime described by panel b of Figure 3 societies that are fundamentally identical may behave differently for prolonged periods.

\subsection{Learning from trade}

So far in our analysis, the information set of group B has been limited to the history of warfare. The inference about group A's type could be improved if agents were able to directly observe part of the trade history. For instance, if public records of the outcome of inter-ethnic trade existed, group B could infer group A's type perfectly. Clearly, this would not be a realistic scenario, since in reality cross-community trade and business links are decentralized and hardly distinguishable from intra-community trade. In this section, we extend the model by assuming that agents are born into (non-altruistic) dynastic families where information can be transmitted from parents to children.

We expand the information set of group B by allowing agents to acquire (stochastically) some information through their trade experience. In particular we assume that in each peaceful period where trade is active, each agent can observe, with a positive probability $\tau$ (i.i.d. across agents), group A's type. Such "hard information" can be transmitted to the agent's offspring 23 In this environment, without additional assumptions, all dynasties would learn perfectly group A's type asymptotically. To prevent the informational friction from vanishing in the long run, we make the realistic assumption that the inter-generational transmission of hard information is subject to frictions: with the exogenous probability $\theta$, an informed parent's child fails to receive the information. In this model, $\theta$ is an inverse measure of the efficiency of learning from trade history, and $1 / \theta$ is the average number of generations to which the information is transmitted.

22. When the uninformative equilibrium region is visited, trust may recover only very slowly, especially if types are very persistent. In particular, as $\psi \rightarrow 1$ and $\phi \rightarrow 1$, the dynamics of 15 which drive the exit from the trap become arbitarily slow.

23. Although we abstract, for simplicity, from horizontal transmission of information within the group, this could be added in principle, as long as one retains some frictions in the transmission process. 
Note that the model of this section nests the benchmark model in the particular case in which $\theta=1$ (or $\tau=0$ ).

In every period there is both a hard information inflow (uninformed traders learning about group A's type) and an exogenous outflow (some informed families forget). In wartime, no one trades and the net inflow necessarily is negative. In peacetime, the net inflow can be positive. Intuitively, information depreciates: if trade was intense in the far past, but then waned due to frequent conflicts, the information gathered through the past trade fades away.

We define by $\iota$ the share of informed agents in group B. The state space is now $(r, \imath) \in$ $\mathbb{R}^{+} \times[0,1]$, specifying the public belief of uninformed agents and the proportion of informed agents. The PBE of the trade game is characterized formally in Supplementary Appendix C, Proposition 9. There, we establish that it is the unique 4-tuple $\left\{n_{A}^{-}, n_{A}^{+}, n_{B}^{-}, n_{B}^{+}\right\} \in[0,1]^{4}$ such that, for $k \in\{-,+\}, n_{A}^{k}\left(r_{P}, \iota\right)=F^{k}\left(z n_{B}^{k}\left(r_{P}, \iota\right)\right)$ and

$$
n_{B}^{k}\left(r_{P}, \iota\right)=\iota F^{B}\left[z F^{k}\left(z n_{B}^{k}\left(r_{P}, \iota\right)\right)\right]+(1-\iota) F^{B}\left[\frac{r_{P}}{1+r_{P}} z F^{+}\left(z n_{B}^{+}\right)+\frac{1}{1+r_{P}} z F^{-}\left(z n_{B}^{-}\right)\right] .
$$

Note that uninformed agents know how many players are informed, but ignore the content of that information. Different from Proposition $2 n_{B}$ depends now on the state $k$, since a proportion $\iota$ of group B players can condition its behaviour on $k$. Note that, in order to set the strategy that maximizes the expected payoff, uninformed players must infer the behaviour of group A conditional on either state of nature, $k \in\{+,-\}$. Since $n_{A}^{k}$ depends on $n_{B}^{k}$, the characterization of equilibrium involves keeping track of both $n_{B}^{+}$and $n_{B}^{-}$, i.e. the proportion of cooperators conditional on the "true" as well as on the "counterfactual" type.

To progress further, we specialize the analysis to a uniform distribution of psychological payoffs $\mathcal{P}$ in both populations. Let $S^{k}\left(r_{P}, \iota\right)$ denote the trade surplus of group A. This depends now on A's type, public beliefs, and the proportion of informed agents in B. Corollary 2 in Supplementary Appendix $\mathrm{C}$ proves that $\partial S^{-} / \partial \iota \leq 0$, whereas $\partial S^{+} / \partial \iota \geq 0$, implying that $\partial\left(S^{+}-S^{-}\right) / \partial \iota \geq 0$. Intuitively, as the share of informed agents increases, the gap in the extent of cooperation across the two states of nature (i.e. $n_{A}^{+}$vs. $n_{A}^{-}$, and $n_{B}^{+}$vs. $n_{B}^{-}$) becomes wider, and is largest as we approach the perfect information equilibrium, $\iota \rightarrow 1$. Such a divergence between the two trade surpluses makes the observation of war/peace more and more informative for any given $r_{P}$, destabilizing the war trap. The comparative statics is shown in Figure 4 drawn for the same parameter values as Figure 1

When $\iota=0$ the schedules $S^{+}$and $S^{-}$are identical to those in Figure 1 and a war trap exists. Increasing $\iota$ to 0.4 reduces the range of posterior beliefs consistent with the existence of the traps. Eventually, as $\iota$ is increased further, the war trap vanishes, as shown by the grey lines in Figure 4 representing the case of $\iota=0.8$. In summary, the larger the share of informed agents, the harder it is to sustain the war trap.

In the rest of the section, we show that the war trap is robust to this environment, when $\iota$ evolves endogenously. Consider the law of motion of $\iota$. The set of informed agents at date $t+1$ comprises children of either uninformed traders who acquired (and did not lose) information at $t$, as long as there was peace, or informed agents at $t$ who did not experience any memory loss. More formally, the law of motion is:

$$
\iota_{t+1}=(1-\theta)\left[\iota_{t}+\left(1-\mathbb{W}_{t}\right) \times \tau \times\left(1-\iota_{t}\right)\right] .
$$

Note that, if $\theta=0$, the share of informed agents would converge to unity since, due to peace shocks, some trade occurs even in the war trap and there is no memory loss. In terms of Figure 4 the schedules $S^{+}$and $S^{-}$would shift progressively outwards every time there is peace, and would 


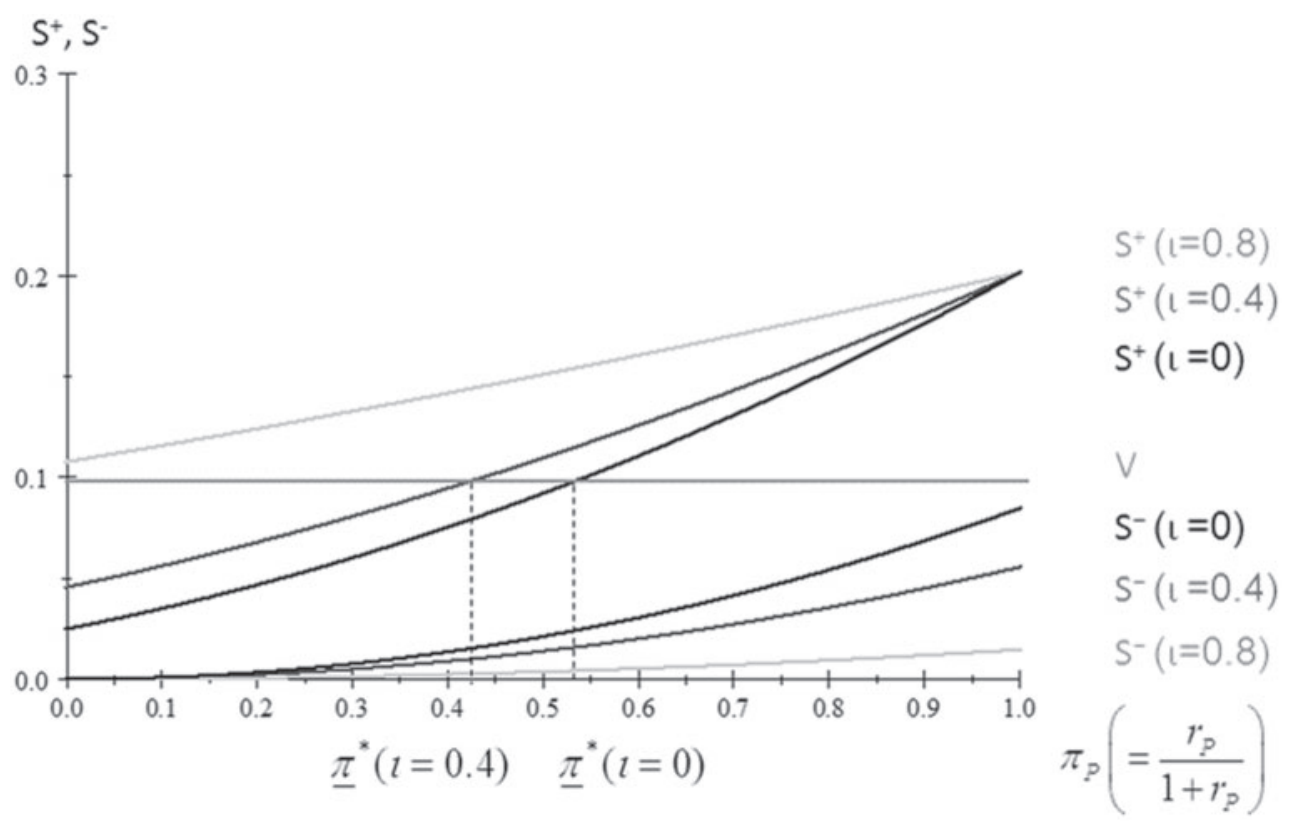

FIGURE 4

Trade surplus with different proportion of informed players, $\iota$

never shift inwards. On the contrary, when $\theta>0$ the share of informed agents can either increase or decrease over time, implying that the schedules $S^{+}$and $S^{-}$can shift either inwards or outwards. Moreover, the share of informed agents is bounded away from unity. In particular, Equation (18) implies that, as long as $\iota_{0}<\iota_{\infty}(\theta) \equiv\left(1+\frac{\theta}{\tau(1-\theta)}\right)^{-1}$, then $\iota_{t}<\iota_{\infty}(\theta)$ for any $t>0$ and for any realization, $\mathbb{W}_{t}$, of the war stochastic process. Note that $\iota_{\infty}(\theta)$ corresponds to the limit to which the economy converges after an infinite sequence of peace shocks $\left(\mathbb{W}_{t}=0\right.$, for all $\left.t\right) 24$

Looking back at Figure 4 a war trap exists if $S^{+}\left(0 ; \iota_{\infty}(\theta)\right)<V$. In this case, the $S^{+}$schedule crosses the horizontal $V$ line for all feasible values of $\iota$. In particular, there exists a low range of public beliefs $(0<r<\underline{r}(\theta))$ such that both the civic and the uncivic type wage war even though the share of informed agents is at its upper bound. In Supplementary Appendix C, we provide a complete closed form characterization of the war trap. We first show that there exists a constant $\theta_{W}<1$ such that a war trap exists if and only if $\theta \geq \theta_{W}$. Then, given $\theta$, we characterize the threshold $\underline{r}(\theta)$ such that, for any $r<\underline{r}(\theta)$ the economy is in a war trap.

When agents learn through trade, it is also possible to observe war cycles. Suppose that group $\mathrm{A}$ is civic and that the economy initially is in the informative region. Suppose, in addition, that $S^{+}\left(0 ; \iota_{\infty}(\theta)\right)>V$, so that there is no war trap. Yet, a sequence of war shocks can push the economy into a region where both groups wage war under BAU, and thus the probability of war is high $\left(1-\lambda_{W}\right)$. Moreover, each war spell brings about the collapse of trade, causing a further reduction in the share of informed agents $(\iota)$ who trust group A. Even though, for any state of the economy, there exist sequences of peace shocks that can bring the economy out of the uninformative region, each war episode makes the economy sink deeper into the vicious cycle

24. The region $\iota>\iota_{\infty}(\theta)$ corresponds to a set of non-recurrent states. If the economy starts in such a set, it abandons it in finite time with probability one. 
of low trust and low trade. Conversely, peace episodes become very important. Although peace is per se no informative public signal, during each peace spell agents trade and informed traders build up and transmit to future generations trust towards the other group. This result is related to Acemoglu and Wolitzky (2012) where trust cycles also hinge on a (different) form of limited memory.

\subsection{Other extensions}

In order to achieve tractability, we have introduced a number of important simplifications. For instance, we have assumed that the net benefits from war are exogenous, and orthogonal to observable and unobservable characteristics of the aggressor, including its propensity to cooperate while trading. Another caveat is that so far the analysis has been restricted to two groups. While a thorough generalization along these and other dimensions is left to future research, in this section we sketch two first-step extensions.

In the first extension, we introduce correlation between group A's propensity to cooperate and the stochastic process $\mathcal{V}$. In particular, we assume that the uncivic type has weaker psychological barriers against attacking the other group. We consider two cases. First, we assume that the benefits of war under BAU are type-dependent: $\mathcal{V}^{k} \in\left\{V_{L}, V^{k}, V_{H}\right\}$, where $k \in\{+,-\}$ and $V^{-}>V^{+}$(the uncivic enjoys war more than does the civic under BAU). In this case, the qualitative results of the benchmark model remain unchanged. A war trap continues to exist, as long as $V^{+}>S^{+}(0)$. Second, we assume that $V^{-}=V^{+}=V$, but the probability of war (peace) shocks is higher when group A is uncivic (civic): $\lambda_{W}^{-}>\lambda_{W}^{+}$and $\lambda_{P}^{-}<\lambda_{P}^{+}$. The probabilities of BAU stay unchanged

$\left(\lambda_{W}^{-}+\lambda_{P}^{-}=\lambda_{W}^{+}+\lambda_{P}^{+}\right)$, for simplicity. The main new result is that the observation of war and peace is now always informative, irrespective of beliefs. Even in the region where both types wage war under BAU, the probability of a peace (war) shock is now higher when A is civic (uncivic), and thus $r_{P}\left(r_{-1}\right)>r_{-1}>r_{W}\left(r_{-1}\right) 25$ Strictly speaking, this extension features no war trap. However, wars become highly frequent and persistent whenever $r<\underline{r}$, since both types wage war under BAU. In that region, every war spell sinks the economy deeper and deeper into the vicious cycle of distrust and low cooperation.

In the second extension (analysed more formally in Supplementary Appendix C), we assume that the economy is inhabited also by a third group, C, which can trade with A. Group A can only wage war against B. During wartime, there is no trade between A and B, but A can trade with $\mathrm{C}$. Trade between $\mathrm{A}$ and $\mathrm{C}$ is subject to no informational friction (for simplicity), but is less productive than trade between $\mathrm{A}$ and $\mathrm{B}$, reflecting the lower skill of group $\mathrm{C}$. The intensity of the link between $\mathrm{A}$ and $\mathrm{C}$ is parameterized by the payoff of their bilateral trade.

This analysis highlights a new interesting implication. If from group A's standpoint trade with $\mathrm{C}$ is a substitute of trade with $\mathrm{B}$, then opening a trade link with a third group increases the range of beliefs such that A wages war on B. Intuitively, the opportunity cost of war is lower if during wartime A can replace the destroyed trade with B with newly created trade with $\mathrm{C}$ (even though

25. More formally, the log-likelihood ratios evolve now as follows:

$$
\begin{aligned}
& \ln r_{P}\left(r_{-1}\right)=\ln r_{-1}+\ln \frac{\lambda_{P}^{+}+\left(1-\lambda_{W}^{+}-\lambda_{P}^{+}\right) \sigma^{+}\left(r_{-1}\right)}{\lambda_{P}^{-}+\left(1-\lambda_{W}^{-}-\lambda_{P}^{-}\right) \sigma^{-}\left(r_{-1}\right)}, \\
& \ln r_{W}\left(r_{-1}\right)=\ln r_{-1}-\ln \frac{1-\lambda_{P}^{-}-\left(1-\lambda_{W}^{-}-\lambda_{P}^{-}\right) \sigma^{-}\left(r_{-1}\right)}{1-\lambda_{P}^{+}-\left(1-\lambda_{W}^{+}-\lambda_{P}^{+}\right) \sigma^{+}\left(r_{-1}\right)} .
\end{aligned}
$$


this trade is less productive) 26 On the contrary, if trade with $\mathrm{C}$ is a complement of trade with $\mathrm{B}$, a stronger trade link between $\mathrm{A}$ and $\mathrm{C}$ reduces the probability of an aggression against $\mathrm{B}$.

For example, if entrepreneurs in group A can hire workers in either group B or C, and these workers have substitutable skills, the availability of workers from $\mathrm{C}$ reduces the economic losses suffered by A during an inter-ethnic war with B. However, if members of group B-alongside trading directly with $\mathrm{A}$ - act as middlemen between $\mathrm{A}$ and $\mathrm{C}$, then the trade link between $\mathrm{A}$ and $\mathrm{C}$ turns into a war deterrent. Intuitively, not only does war disrupt the trade between $\mathrm{A}$ and $\mathrm{B}$, but it also causes collateral damage to the trade between $\mathrm{A}$ and $\mathrm{C}$. In the next section, we show that these predictions are consistent with the empirical evidence that the probability of inter-ethnic conflict is indeed higher when groups hold substitutable skills rather than complementary skills.

\section{TRADE AND CIVIL CONFLICT: EVIDENCE FROM CASE STUDIES}

In this section, we document case-study evidence of the link connecting trust, inter-ethnic trade (or, more generally, social interaction), and war.

The surplus of inter-ethnic trade clearly depends on how much different communities are specialized in complementary activities, as we discuss in Section 6.3 In line with this prediction, Horowitz (2000) shows that strong economic inter-group complementarities contribute to interethnic peace. Examples include Indonesia, Myanmar, Malaysia, and India where middleman minorities often have been shielded from political violence, as they provide valuable services to the local ethnic majority. A similar conclusion is reached by Jha (2008) who studies HinduMuslim interactions using town-level data for India. He finds that during medieval times in India's trade ports, Hindus and Muslims provided complementary services to each other, and argues that this business interaction led to religious tolerance and a lower level of political violence in these trade ports than in other Indian towns. Interestingly, this kind of situation persists today. In a similar vein, Varshney $(2001,2002)$ argues that the existence of inter-ethnic business and civic associations can stunt the potential for riots in India. According to Varshney, for the prevention of ethnic conflict "trust based on interethnic, not intraethnic, networks is critical" (2001: 392). Bardhan (1997) discusses how waning inter-ethnic business links, due to exogenous factors lowering the opportunity costs of conflict, resulted in the outbreak of riots 27 Moving to Africa, Olsson (2010) shows that an exogenous change in climatic conditions (i.e. a severe drought) has brought to a collapse of the inter-ethnic trade between farmers and herders in Sudan's Darfur region, and that this breakdown has been followed by the outbreak of conflict 28 Similarly, Porter et al. (2010) carry out in-depth interviews with market traders in areas of Nigeria characterized by inter-ethnic tensions, and find that the existence of inter-ethnic trade links prevents the outbreak of full-blown riots.

26. Similar implications obtain in a model where, in peacetime, $\mathrm{C}$ trades with $\mathrm{B}$, regarded to be a better partner than A. A successful attack of A on B destroys any trade involving B, eventually forcing C to trade with A. In this case, the competition motive strengthens the drive to attack B.

27. "On the Moradabad riots of 1980: The higher wages in the brass industry and entrepreneurship brought about not only greater prosperity among the Muslims, it also began to lessen the importance of the middlemen, often Hindu, in business transactions. Some of the Muslim entrepreneurs even managed to get direct orders from West Asian countries. The Hindu middlemen thus edged out began to rally round the Jan Sangh (now BJP) which has its base among petty businessmen" (Bardhan, 1997: 1397).

28. Also UNICEF (2003) finds that exogenous collapses in inter-ethnic markets have resulted in conflicts in Darfur: "The groups confronting each other in the current conflicts have a long history of guarded cooperation and relative peaceful coexistence. In the past, they exchanged goods and services; indeed some of the herds that the Arab nomads reared belonged to wealthy Fur who did not opt to become nomads themselves. The Fur sold most of their herds on the onset of the drought in 1982/83. This was considered a severance of economic relations, which strained the relations between the Fur and the Arabs" (UNICEF, 2003: 53). 
Another prediction of our theory is that, whenever war depletes trust, inter-group trade tends to collapse. In line with this prediction, Guiso et al. (2009) provide evidence of a causal negative effect of the long-run intensity of bilateral warfare (over the 1000-1970 period) on the current level of bilateral trust and trade in a sample of European countries (see also Glick and Taylor, 2010). Looking at a more recent episode, in Rohner et al. (2011) we find that post-conflict economic recovery in Uganda was especially slow in counties that both had been subject to intensive fighting and were more ethnically fractionalized (an interaction effect), likely because of the collapse of inter-ethnic business cooperation. Similarly, Cassar et al. (2011) find that exposure to ethnic conflict in Tajikistan undermined the former victims' willingness to participate in market activity involving trade with people with whom they do not have a personal connection.

Trust, trade, and conflict appear to have been intertwined in Rwanda. Case studies from Ingelaere (2007) and Pinchotti and Verwimp (2007) document that throughout the 1980s interethnic trust was relatively high and sustained symbiotic business relationships, cooperation in agricultural production associations and mixed rotating savings groups involving both Hutus and Tutsis. Survey data indicate that trust plummeted as of 1990, after localized ethnic fighting erupted in northern Rwanda (Ingelaere, 2007). The collapse of trust was followed by fading trade and business links between the communities, until inter-ethnic cooperation ceased altogether at the onset of the 1994 genocide 29 Even several years after the conflict, the average inter-ethnic trust levels are significantly lower than in the 1980s (Ingelaere, 2007), and also inter-ethnic trade is persistently low (Colletta and Cullen, 2000).

Similarly, UNICEF (2003) documents that in several of Darfur's conflicts inter-group trust and trade broke down in the aftermath of fighting. For example, the civil war has resulted in the disintegration of the traditional economic arrangements between nomads and farmers regulating the use of pastureland and access to water in the Upper Nile region. This collapse of economic cooperation spurred kidnapping and other forms of inter-ethnic violence, triggering more local conflicts. The same pattern is also found elsewhere in Africa. Dercon and GutierrezRomero (2012) study the 2007 Kenyan electoral violence. Their survey data indicate that violence decreased trust between ethnic groups (while increasing trust within ethnic groups). Furthermore, after episodes of violence, people indicated that they tend to do less business with people from other ethnic groups and that they find violence more justifiable.

There are also case studies documenting the detrimental effect of war on trust and trade in Europe. Blagojevic (2009) finds that after the Bosnian war inter-ethnic trust collapsed and that the economic cooperation between the Serbian population on the one hand, and the Bosnian and Croatian population on the other declined sharply, being often replaced by intense inter-ethnic competition. Similarly, according to Kaufman (1996) the war in Moldova ushered in a climate of distrust between the Moldavans and the Russian-speaking minority, and ultimately a substantial decline in inter-ethnic business cooperation.

\section{POLICY IMPLICATIONS}

Our model implies that policies intended to increase the return from inter-ethnic trade-e.g. by reducing cross-community trade frictions, or facilitating the economic integration of minoritiesincrease the opportunity cost of war, narrowing the range of beliefs that sustain war traps 30

29. Colletta and Cullen, (2000: 45) find that while vertical (within-group) social capital remained intact, "conflict deeply penetrated such forms of horizontal social capital as exchange, mutual assistance, collective action, trust and the protection of the vulnerable... The use of credit in exchanges was common in preconflict Rwanda. This practice has diminished over time, in part due to decreased levels of trust as a consequence of warfare".

30. While we have assumed, for simplicity, that the matching process is frictionless, one can easily extend the model to incorporate search frictions. In this environment, only a fraction of the agents seeking partnerships would be 
Formally, scaling up the economic pay-off of the stag hunt game causes an upward shift of both $S^{+}$and $S^{-}$in Figure 1 shifting $\frac{\pi}{2}$ to the left, and possibly even ruling out the trap altogether. This prediction lines up with the empirical results of Horowitz (2000) on affirmative action and ethnic conflict. He finds that preferential programs aiming to improve the integration of less advanced ethnic groups in the national economy have reduced the potential for conflict in various countries such as India, Indonesia, Malaysia, and Nigeria 31 Since trade typically thrives in fast-growing economies, our theory is also broadly consistent with the evidence that high economic growth reduces the risk of war recurrence (Sambanis, 2008; Walter, 2004). The theory also suggests a role for policy incentivizing inter-ethnic cooperation (in our model, increasing $z$ ). For instance, improving contract enforcement and punishing fraudulent behaviour in business relationships would reduce the payoff of cheating and opportunistic behaviour, thereby increasing the trade surplus. In the alternative interpretation of the trade game provided in Section $2.1 z$ could be increased by policies supporting human capital formation, such as promoting the knowledge of multiple national languages or of other cultural aspects that affect inter-ethnic barriers. This finding is in line with the evidence that higher education expenditures and enrollment rates decrease the risk of civil wars (Thyne, 2006).

To the opposite, larger windfall gains from war (i.e. larger $V$ ) expand the potential for war traps. For instance, the discovery of oilfields or diamond mines can drive an economy in which trust was initially low into a war trap, while the same discovers would have no detrimental effects in economies where trust and cooperation were high in the first place. Here the predictions of our theory conform well with the evidence that more abundant natural resources fuel war recurrence and hinder post-war recovery in fragile states dominated by low trust (see, e.g. Doyle and Sambanis, 2000; Fortna, 2004; Sambanis, 2008), while typically they have no harmful consequences in high-trust strong states like Norway. International sanctions, such as embargoes on arms or on natural resource imports from regimes that have seized power through ethnic wars could reduce $V$.

Our theory has ambiguous implications about the effectiveness of international peacekeeping. The benchmark model predicts that international peacekeeping interventions limited to "stopping the shooting" will have only short-lasting effects on political stability. External military-backed peacekeeping may even be detrimental, if local groups attribute any peace episode to the mere presence of foreign troops, and then stop updating beliefs. However, according to the extension of Section 6.2 even an externally imposed truce can be useful if it restores some inter-ethnic trade that induces some learning and trust rebuilding. The nature of the peace-keeping intervention becomes therefore crucial: If the intervention simply keeps the fighting groups apart, it will not achieve permanent effects. Yet, if peacekeeping is first complemented and then replaced by trade- and trust-enhancing measures, it can be effective. These ambiguous predictions are in line with the gloomy appraisal of a variety of studies on the survival of peace. According to Sambanis (2008: 30): "UN missions have a robust positive effect on peacebuilding outcomes, particularly participatory peace, but the effects occur mainly in the short run and are stronger when peacekeepers remain." Luttwak (1999: 37) goes further, and argues that mere peacekeepingunless accompanied by trade-promoting or trust-restoring measures-does not lead to lasting

able to trade. The stronger the frictions, the lower the trade surplus. Active integration policies reducing such frictions would ultimately shrink the range of war traps.

31. Horowitz (2000) and Whah (2010) show that the programs of state-induced inter-ethnic joint venture companies in Malaysia dating from the 1970s have in many instances enhanced trust between the Malay and the Chinese population reducing social tensions. Similarly, Augenbraun et al. (1999) find that microenterprise lending by donors in Bosnia for inter-ethnic joint ventures has worked well, not only in a purely economic sense, but also calming tensions between groups. 
peace; it simply interrupts hostilities that will recur once the UN troops leave: "(Peacekeeping), perversely, can systematically prevent the transformation of war into peace. The Dayton accords are typical of the genre: they have condemned Bosnia to remain divided into three rival armed camps, with combat suspended momentarily but a state of hostility prolonged indefinitely ... Because no path to peace is even visible, the dominant priority is to prepare for future war rather than to reconstruct devastated economies and ravaged societies."

Our theory also suggests that policies directly targeting beliefs may be important when distrust hinges on no fundamental reasons (in the model, $k=+$ ), yet cooperation is hindered by bad beliefs. In such cases, creating pro-trade public information, for instance by documenting and publicizing successful episodes of inter-ethnic business cooperation, can help end the vicious cycle. There is indeed empirical evidence that inter-group prejudices can be weakened by targeted media exposure (Paluck, 2009; Paluck and Green, 2009). According to Paluck's (2009) findings the listeners exposed to the "social reconciliation" radio soap opera in Rwanda were significantly more likely to find it "not naive to trust" and to feel empathy for other Rwandans than the control group exposed to a "health" radio soap opera. Similarly, Bardhan (1997) shows that in India direct targeting of Muslims' and Hindus' beliefs by spreading success stories of cooperation has reduced distrust and the potential for conflicts: "Public information on what actually happened, on how a disturbance started, on who tried to take advantage of it, on instances of intercommunity cooperation in the face of tremendous odds, etc., if effectively transmitted in the early stages, can stop some of the vicious rumors that fuel communal riots and calm group anxieties" (Bardhan, 1997: 1395).

Finally, when the fundamentals are bad (in the model, $k=-$ ), public campaigns aimed to shift collective preferences may be effective. Such campaigns may aim either to foster procooperative norms, or to eradicate prejudice and dislike towards specific communities (both cases can be modelled as shifts in the distribution of $\mathcal{P}$ ). For instance, Hauk and Saez-Marti (2002) document that a strong press and education campaign was key to slashing corruption and opportunistic practices in Hong Kong during the 1970s. Denazification after the Second World War is an example in which the campaign targeted people's preferences pointedly, aiming to eradicate racial hatred against minorities. In terms of our model, these campaigns may be viewed as measures to promote cultural shifts, such as those happening exogenously in Section 6.1 While the statement that campaigns against racial hatred can reduce conflict may sound obvious, our theory warns that such campaigns may be of limited help if they do not target, simultaneously, the beliefs (trust) of the victims. For instance, our model of Section 6.1 shows that if group B perceives a change of group A's type to be very unlikely (case 1), even a campaign that successfully turns group A from uncivic to civic may prove ineffective. This issue is salient in countries prone to civil conflicts where the ethnic group in majority replaces a radical sectarian government with a more inclusive one, but fails to restore the confidence of minorities.

While the theory suggests a number of useful policy implications, a caveat is that these are valid under a set of specific assumptions that may not capture salient aspects of particular conflicts. We focus on a broad category of inter-group social interactions taking the form of a stag hunt game. However, there may be other forms of inter-group interactions with different payoff structures and incentives. For instance, recent empirical literature shows that ethnic diversity may have different effects depending on whether cross-group interactions are about rival (private) or non-rival (public) goods (Esteban et al., 2012; Spolaore and Wacziarg, 2012).

\section{CONCLUSION}

This article provides a theory in which asymmetric information and cultural transmission of beliefs can explain why societies enter into recurrent civil conflicts even when there is no 
fundamental reason for conflicts to occur. We emphasize the link between trade and war, which has been highlighted in the recent literature on international conflicts. We believe that this connection can be even more salient in inter-group conflicts within countries where business relationships are decentralized and do not need the mediation of institutions that can aggregate and diffuse information. Our discussion has emphasized the role of inter-ethnic trade, which we hold to be especially important. However, our theory can be extended to a broader set of social interactions within countries, including inter-ethnic marriages, public good provision in villages and communities, and more general situations involving bilateral cooperation across ethnic cleavages.

While our current study presents a rational-agent theory, integrating psychological aspects may reveal more about these issues. For instance, exposure to war during childhood may be especially important, since many beliefs and values are formed at tender ages. In our model, heterogeneous preferences are exogenous, while in reality these may be shaped by parental transmission, as in Hauk and Saez-Marti (2002). Our analysis also abstracts from general equilibrium effects that may affect the opportunity costs of wars and the returns to violent resource appropriation (as emphasized by Dal Bo and Dal Bo, 2011). Finally, we have abstracted from institutions and state capacity (Besley and Persson, 2010). As emphasized by Aghion et al. (2011), institutions and beliefs are not independent factors: on the one hand, institutions can affect the trust-building process, while on the other trust can influence institutional developments that can deter conflict. Reforming institutions in a more inclusive direction (in the sense of Acemoglu and Robinson, 2012) can help build inter-ethnic trust and trade. Studying these interconnections is left to future research.

\section{Appendix I}

Proof of Propositions 1 and 2 The proof of Proposition 2 encompasses the proof of Proposition 1 since perfect information is a particular case of imperfect information, where either $\pi_{P}=0$ (if $k=-$ ) or $\pi_{P}=1$ (if $k=+$ ).

We start by proving that a PBE exists. Given the definition $\pi_{P} \equiv \frac{r_{P}}{1+r_{P}}$, we can write the third element of Equation 44 as

$$
n_{B}=\tilde{F}^{B}\left(n_{B}, \pi_{P}\right) \equiv F^{B}\left(\pi_{P} z F^{+}\left(z n_{B}\right)+\left(1-\pi_{P}\right) z F^{-}\left(z n_{B}\right)\right) .
$$

We claim three properties of $\tilde{F}^{B}:$ (i) $\tilde{F}^{B}:[0,1]^{2} \rightarrow[0,1]$ is a continuous function, with $0<\tilde{F}^{B}\left(n_{B}, \pi_{P}\right)<1$; (ii) $\tilde{F}^{B}\left(n_{B}, \pi_{P}\right)$ is increasing in $\pi_{P}$, for any $n_{B}$; (iii) $\tilde{F}^{B}\left(n_{B}, \pi_{P}\right)$ is non-decreasing and convex in $n_{B}$, for any $\pi_{B}$.

Note, first, that Assumption 1 implies that $F^{B}, F^{+}$, and $F^{-}$are continuous non-decreasing convex functions. Then, (i) follows from the fact that $\tilde{F}^{B}$ is a convex combination of two c.d.f.'s, $F^{+}$and $F^{-}$, which are continuous functions. Assumption 1 guarantees that $0<\tilde{F}^{B}\left(n_{B}, \pi_{P}\right)<1$; (ii) follows from the fact that $\tilde{F}^{B}$ is a convex combination of two c.d.f.'s $F^{+}$and $F^{-}$, with weights $\pi_{P}$ and $1-\pi_{P}$, respectively, where $F^{-}\left(z n_{B}\right)<F^{+}\left(z n_{B}\right)$ which in turn follows from the assumption that $H^{+}$first-order stochastically dominates (FOSD) $H^{-}$; (iii) follows from the fact that $\tilde{F}^{B}$ is a non-decreasing convex transformation of the convex combination of two non-decreasing convex functions of $n_{B}$.

Given (i), the existence, for any given $\pi_{P} \in[0,1]$, of $n_{B}=n_{B}^{*}\left(\pi_{P}\right)$ satisfying A.1 follows from the Brouwer fixedpoint theorem. Since $0<\tilde{F}^{B}\left(n_{B} ; \pi_{P}\right)<1$, then the fixed-point of A.1 must be strictly within the unit interval. (ii) and (iii) guarantee that the mapping $n_{B}^{*}\left(\pi_{P}\right)$ is unique and is monotonically weakly increasing. We prove uniqueness by contradiction. Assume that, for some $\pi_{P}$, there exists a second fixed point $\hat{n}_{B}=\tilde{F}^{B}\left(\hat{n}_{B} ; \pi_{P}\right)$. Without loss of generality, let $n_{B}^{*}\left(\pi_{P}\right)<\hat{n}_{B}$. The second fixed point, $\hat{n}_{B} \in\left[n_{B}, 1\right]$, can be expressed as the convex combination $\hat{n}_{B}=\frac{1-\hat{n}_{B}}{1-n_{B}^{*}\left(\pi_{P}\right)} \times n_{B}^{*}\left(\pi_{P}\right)+$ $\frac{\hat{n}_{B}-n_{B}^{*}(\pi P)}{1-n_{B}^{*}(\pi P)} \times 1$. Then, applying to $\hat{n}_{B}$ the convexity criterion of $\tilde{F}^{B}$ yields

and this leads to

$$
\tilde{F}^{B}\left(\hat{n}_{B} ; \pi_{P}\right) \leq \frac{1-\hat{n}_{B}}{1-n_{B}^{*}\left(\pi_{P}\right)} \tilde{F}^{B}\left(n_{B}^{*}\left(\pi_{P}\right) ; \pi_{P}\right)+\frac{\hat{n}_{B}-n_{B}^{*}\left(\pi_{P}\right)}{1-n_{B}^{*}\left(\pi_{P}\right)} \tilde{F}^{B}\left(1 ; \pi_{P}\right)
$$

$$
\hat{n}_{B} \leq \frac{1-\hat{n}_{B}}{1-n_{B}^{*}\left(\pi_{P}\right)} n_{B}^{*}\left(\pi_{P}\right)+\frac{\hat{n}_{B}-n_{B}^{*}\left(\pi_{P}\right)}{1-n_{B}^{*}\left(\pi_{P}\right)} \tilde{F}^{B}\left(1 ; \pi_{P}\right),
$$

which in turn implies (since $n_{B}^{*}\left(\pi_{P}\right)<\hat{n}_{B}$ ) that $\tilde{F}^{B}\left(1 ; \pi_{P}\right)>1$, contradicting property (i). This establishes the uniqueness of the equilibrium mapping $n_{B}^{*}\left(\pi_{P}\right)$. That $n_{B}^{*}\left(\pi_{P}\right)$ is monotonically weakly increasing follows immediately from claim (ii). 
Next, define $n_{B}^{*}\left(\pi_{P}\right)=n_{B}^{*}\left(\frac{r_{P}}{1+r_{P}}\right) \equiv n_{B}\left(r_{P}\right)$. The analysis above establishes that the function $n_{B}\left(r_{P}\right)$ exists, is unique, is weakly increasing and lies strictly within the unit interval. That the same properties carry over to $n_{A}^{-}\left(r_{P}\right)=F^{-}\left(z n_{B}\left(r_{P}\right)\right)$ and $n_{A}^{+}\left(r_{P}\right)=F^{+}\left(z n_{B}\left(r_{P}\right)\right)$ is immediate. Thus, Equation 4 has a unique fixed point. Since $F^{-} \operatorname{FOSD} F^{+}$, then $n_{A}^{-}\left(r_{P}\right) \leq$ $n_{A}^{+}\left(r_{P}\right)$. This proves the first part of the proposition.

The formula of the trade surplus is derived from integrating by parts $\int_{-\infty}^{z n_{B}\left(r_{P}\right)} \mathcal{L} d F^{k}=-\left[\mathcal{L} F^{k}\right]_{-\infty}^{z n_{B}\left(r_{P}\right)}+$ $\int_{-\infty}^{z n_{B}\left(r_{P}\right)} F^{k}(\mathcal{L}) d \mathcal{L}$, where $\left[\mathcal{L} F^{k}\right]_{-\infty}^{z n_{B}\left(r_{P}\right)}=z n_{A}^{k}\left(r_{P}\right) n_{B}\left(r_{P}\right)$, and simplifying terms. Since $F^{k}$ is non-negative and $n_{B}\left(r_{P}\right)$ is non-decreasing, then $S^{k}\left(r_{P}\right)$ must be non-decreasing. That $S^{-}\left(\pi_{P}\right) \leq S^{+}\left(\pi_{P}\right)$, finally, follows again from the fact that $F^{-}$ FOSD $F^{+}$. Q.E.D.

Proof of Lemma We proceed in two steps: (i) we prove that an uninformative PBE exists if and only if $r_{-1} \leq \underline{r}^{*}$; (ii) we prove that informative PBE exist if and only if $r_{-1} \geq \underline{r}$. (i) and (ii) together prove the Lemma.

(i) First, we prove (by guess-and-verify) that an uninformative PBE exists if $r_{-1} \leq \underline{r}^{*}$. Guess that an uninformative PBE exists. Then, $r_{-1} \leq \underline{r}^{*} \Rightarrow r_{P}\left(r_{-1}\right)=r_{-1} \leq \underline{r}^{*}$, which in turn implies that $V \geq S^{+}\left(r_{P}\left(r_{-1}\right)\right)>S^{-}\left(r_{P}\left(r_{-1}\right)\right)$. Thus, $\sigma^{+}\left(r_{-1}\right)=\sigma^{-}\left(r_{-1}\right)=0$, verifying the guess. Second, we prove (by contradiction) that an uninformative PBE exists only if $r_{-1} \leq \underline{r}^{*}$. Suppose that an uninformative PBE exists in the range $r_{-1}>\underline{r}^{*}$. Then, by the definition of uninformative equilibrium, $r_{P}\left(r_{-1}\right)=r_{-1}>\underline{r}^{*}$, which in turn implies that $S^{+}\left(r_{P}\left(r_{-1}\right)\right)>V$ and $S^{-}\left(r_{P}\left(r_{-1}\right)\right)<V$. Thus, $\sigma^{+}\left(r_{-1}\right)=1$ and $\sigma^{-}\left(r_{-1}\right)=0$, contradicting that the PBE is uninformative.

(ii) First, we prove (by guess-and-verify) that informative PBE exist if $r_{-1} \geq \underline{r}$. Guess that an informative PBE exists such that $\sigma^{+}\left(r_{-1}\right)=1$ and $\sigma^{-}\left(r_{-1}\right)=0$ (note: it can be established that a mixed strategy equilibrium such that $0<\sigma^{+}\left(r_{-1}\right)<1$ and $\sigma^{-}\left(r_{-1}\right)=0$ also exists in this range, but this is not essential to prove the Lemma, so the proof is omitted). Then, $r_{-1} \geq \underline{r} \Rightarrow \infty>r_{P}\left(r_{-1}\right) \geq \underline{r}^{*}$, which in turn implies that $S^{-}\left(r_{P}\left(r_{-1}\right)\right)<V \leq S^{+}\left(r_{P}\left(r_{-1}\right)\right)$. Thus, $\sigma^{+}\left(r_{-1}\right)=1$ and $\sigma^{-}\left(r_{-1}\right)=0$, verifying the guess. Second, we prove (by contradiction) that an informative PBE exists only if $r_{-1} \geq \underline{r}$. Suppose that an informative PBE exists in the range $r_{-1}<\underline{r}$. Then, $r_{-1}<\underline{r} \Rightarrow r_{P}\left(r_{-1}\right)<\underline{r}^{*}$, which in turn implies that $V>S^{+}\left(r_{P}\left(r_{-1}\right)\right)>S^{-}\left(r_{P}\left(r_{-1}\right)\right)$. Thus, $\sigma^{+}\left(r_{-1}\right)=\sigma^{-}\left(r_{-1}\right)=0$, contradicting that the equilibrium is informative. Q.E.D.

Proof of Proposition 5 The process $\pi_{t}$ is a bounded non-negative martingale. Hence, the Martingale Convergence Theorem implies that, almost surely, the limit $\pi_{\infty}=\lim _{t \rightarrow \infty} \pi_{t}$ exists and is unique. Let $\Gamma_{\infty}^{k}$ denote the support of $\pi_{\infty}$ when group A's type is $k \in\{-,+\}$. Let $\left.\left.\tilde{\Omega}_{T R A P}=\right] \underline{r} /\left(\frac{1-\lambda_{P}}{\lambda_{W}}+\underline{r}\right), \underline{r} /(1+\underline{r})\right]$ denote the war trap (in term of the state space of beliefs, $\left.\pi_{t}\right)$ without the range of non-recurrent states, $\left[0, \underline{r} /\left(\frac{1-\lambda_{P}}{\lambda_{W}}+\underline{r}\right)\right]$. Also, let the open set $\left.\Gamma_{I}=\right] \frac{r}{1+\underline{r}}, 1[$ denote the interior of the informative region.

We start by proving two key results: (1) for any $k \in\{-,+\}, \Gamma_{I} \cap \Gamma_{\infty}^{k}=\varnothing$; (2) $1 \notin \Gamma_{\infty}^{-}$(i.e. when $k=-, \pi_{t}$ cannot converge to the "wrong" perfect learning). Both claims are proven by contradiction.

1. Suppose that $\pi_{\infty} \in \Gamma_{I}$. Then, there exists $T<\infty$ such that, for all $t \geq T, \pi_{t} \in \Gamma_{I}$. Next, recall that within the informative region the dynamics of (the likelihood ratio of) beliefs is governed by 9 . Taking limits as $t \rightarrow+\infty$ and replacing $r$ by its definition yields: $\lim _{t \rightarrow \infty}\left(\ln r_{t}-\ln r_{t-1}\right)=\ln \frac{\pi_{\infty}}{1+\pi_{\infty}}-\ln \frac{\pi_{\infty}}{1+\pi_{\infty}}=0=$ $\lim _{t \rightarrow \infty}\left(\left(1-\mathbb{W}_{t}\right) \ln \left(\frac{1-\lambda_{W}}{\lambda_{P}}\right)-\mathbb{W}_{t} \ln \left(\frac{1-\lambda_{P}}{\lambda_{W}}\right)\right)$. This is a contradiction, since the last term does not converge.

2. Suppose that $k=-$ and $\pi_{\infty}=1$. Then, there exists $T<\infty$ such that, for all $t \geq T, \pi_{t}$ must remain forever in the informative region $\left(\pi>\frac{r}{1+\underline{r}}\right)$. But then, the Strong Law of Large Numbers implies that, as $t \rightarrow \infty$, the empirical frequencies of war/peace converge to the true underlying probabilities. Then, we should have that $\pi_{\infty}=0$, leading to a contradiction.

(1) and (2) jointly establish that, (i) if $k=-$, then $\Gamma_{\infty}^{-} \subset \tilde{\Omega}_{T R A P}$ (the DSE enters the war trap almost surely); (ii) if $k=+$, then $\Gamma_{\infty}^{+} \subset \tilde{\Omega}_{T R A P} \cup\{1\}$ (the DSE either enters the war trap or converges to truthful learning).

Let $\mathbb{P}_{T R A P} \equiv \mathbb{P}\left[\pi_{\infty} \in \tilde{\Omega}_{T R A P} \mid k=+\right]$. Since $\pi_{t}$ is a martingale, then, $\pi_{0}=\mathbb{E}\left[\pi_{t}\right], \forall t$. Moreover,

$$
\begin{aligned}
\pi_{0} & =\lim _{t \rightarrow \infty} \mathbb{E}_{0}\left[\pi_{t}\right] \\
& =\pi_{0} \times \mathbb{E}\left[\pi_{\infty} \mid k=+\right]+\left(1-\pi_{0}\right) \times \mathbb{E}\left[\pi_{\infty} \mid k=-\right],
\end{aligned}
$$

where

$$
\mathbb{E}\left[\pi_{\infty} \mid k=+\right]=\mathbb{P}_{T R A P} \times \mathbb{E}\left[\pi_{\infty} \mid k=+, \pi_{\infty} \in \tilde{\Omega}_{T R A P}\right]+\left(1-\mathbb{P}_{T R A P}\right) \times 1 .
$$

Combining A.2 and A.3 we obtain, after standard algebra,

$$
\mathbb{P}_{\text {TRAP }}=\frac{1-\pi_{0}}{\pi_{0}} \frac{\mathbb{E}\left[\pi_{\infty} \mid k=-\right]}{1-\mathbb{E}\left[\pi_{\infty} \mid k=+, \pi_{\infty} \in \tilde{\Omega}_{T R A P}\right]} .
$$


From the definition of $\tilde{\Omega}_{T R A P}$ we immediately obtain $\frac{r}{\frac{1-\lambda}{\lambda_{W}}+\underline{r}}<\mathbb{E}\left[\pi_{\infty} \mid k=+, \pi_{\infty} \in \tilde{\Omega}_{T R A P}\right] \leq \frac{r}{1+\underline{r}}$. Similarly, since $\Gamma_{\infty}^{-} \subset$ $\tilde{\Omega}_{T R A P}$, then $\frac{\underline{r}}{\frac{1-\lambda}{\lambda W}+\underline{r}}<\mathbb{E}\left[\pi_{\infty} \mid k=-\right] \leq \frac{r}{1+\underline{r}}$. Combining these two inequalities with A.4, and using the definition $r_{0} \equiv$ $\frac{\pi_{0}}{1-\pi_{0}}$ yields, after standard algebra, 10 . This completes the proof of Proposition 5 Q.E.D.

Proof of Corollary $\square$ Consider now the case of Corollary $1 \lambda_{W}=\lambda_{P}=\lambda$. In this case, the state space of the stochastic process 9 is isomorphic to $\mathbb{Z}$ : at any time horizon, the termination value of the process is fully characterized by the initial condition and by the total number of wars minus the total number of peace episodes (e.g. the termination value is the same after the sequence war-war-peace as after the sequence peace-war-war). This implies that, given $\pi_{0}$, the set of possible realizations belonging to the war trap, $\pi_{\infty} \in \tilde{\Omega}_{T R A P}$, is reduced to a singleton $\underline{\pi}\left(\pi_{0}\right)$ characterized by $\frac{\pi\left(\pi_{0}\right)}{1+\underline{\pi}\left(\pi_{0}\right)} \equiv \frac{\pi_{0}}{1+\pi_{0}}\left(\frac{\lambda}{1-\lambda}\right)^{\Delta\left(r_{0}\right)}$ and $\Delta\left(r_{0}\right) \equiv\left\lceil\left(\ln r_{0}-\ln \underline{r}\right) /(\ln (1-\lambda)-\ln \lambda)\right\rceil$. Hence, $\Gamma_{\infty}^{+}=\left\{\underline{\pi}\left(\pi_{0}\right)\right\} \cup\{1\}$ and $\Gamma_{\infty}^{-}=\left\{\underline{\pi}\left(\pi_{0}\right)\right\}$. Consequently, $\mathbb{E}\left[\pi_{\infty} \mid k=-\right]=\mathbb{E}\left[\pi_{\infty} \mid k=+, \pi_{\infty} \in \tilde{\Omega}_{T R A P}\right]=\underline{\pi}\left(\pi_{0}\right)$. Thus, Equation A.4 simplifies to $\mathbb{P}_{\text {TRAP }}=\frac{1-\pi_{0}}{\pi_{0}} \frac{\underline{\pi}\left(\pi_{0}\right)}{1-\underline{\pi}\left(\pi_{0}\right)}=\left(\frac{\lambda}{1-\lambda}\right)^{\Delta\left(r_{0}\right)}$. This concludes the proof of Corollary 1 Q.E.D.

Acknowledgments. For comments on this article, we are grateful to Philipp Kircher, the editor, three anonymous referees, and Daron Acemoglu, Philippe Aghion, Alberto Alesina, Roland Benabou, Joan Esteban, Julien Hugonnier, Massimo Morelli, Jody Ono, Gerard Padro i Miquel, Maria Saez-Marti, Gilles Saint-Paul, Pierre Yared, as well as conference participants at the CEPR conference on Political Economy of Development, NBER Summer Institute, Nemmers Prize conference, IAE concentration on conflict, SED annual meeting, and seminar participants at CREi, Paris School of Economics, SciencesPo Paris, Tilburg University, Toulouse School of Economics, University of Geneva, University of Lausanne, University of Oslo, and University of Zurich. D. R. acknowledges financial support from the Swiss National Science Foundation (grant no. 100014-122636). M. T. acknowledges financial support from the ERC Starting Grant GRIEVANCES-313327. F. Z. acknowledges financial support from the ERC Advanced Grant IPCDP-229883.

\section{Supplementary Data}

Supplementary data are available at Review of Economic Studies online.

\section{REFERENCES}

ACEMOGLU, D. and ROBInSON, J. (2012), Why Nations Fail: The Origins of Power, Prosperity, and Poverty (New York: Crown Publishing).

ACEMOGLU, D., TICCHI, D. and VINDIGNI, A. (2010), "Persistence of Civil Wars", Journal of the European Economic Association, 8, 664-676.

ACEMOGLU, D. and ZILIBOTTI, F. (1997), "Was Prometheus Unbound by Chance? Risk, Diversification, and Growth", Journal of Political Economy, 105, 709-751.

ACEMOGLU, D. and WOLITZKY, A. (2012), "Cycles of Distrust: An Economic Model”. (NBER Working Paper No. w18257).

AGHION, P., ALGAN, Y. and CAHUC, P. (2011), "Civil Society and the State: The Interplay between Cooperation and Minimum Wage Regulation”, Journal of the European Economic Association, 9, 3-42.

AGHION, P., ALGAN, Y., CAHUC, P. and SHLEIFER, A. (2010), "Regulation and Distrust", Quarterly Journal of Economics, 125, 1015-1049.

AUGENBRAUN, E., FELD, K., GUEST, I. and MERRILL, S. (1999), "Reconciling Ethnic Conflicts: A Case Study of Bosnia-Herzegovina and Croatia". (USAID Evaluation Special Study 80).

BALIGA, S. and SJOSTROM, T. (2004), “Arms Races and Negotiations”, Review of Economic Studies, 71, 351-369.

BANERJEE, A. (1992), “A Simple Model of Herd Behavior”, Quarterly Journal of Economics, 107, 797-817.

BARDHAN, P. (1997), "Method in the Madness? A Political-Economy Analysis of the Ethnic Conflicts in Less Developed Countries", World Development, 25, 1381-1398.

BESLEY, T. and PERSSON, T. (2010), "State Capacity, Conflict and Development", Econometrica, 78, 1-34.

BESLEY, T. and PERSSON, T. (2011), "The Logic of Political Violence", Quarterly Journal of Economics, 126, $1411-1445$.

BIKHCHANDANI, S., HIRSHLEIFER, D. and WELCH, I. (1992), "A Theory of Fads, Fashion, Custom, and Cultural Change as Information Cascades", Journal of Political Economy, 100, 992-1026.

BLAGOJEVIC, B. (2009), "Causes of Ethnic Conflict: A Conceptual Framework", Journal of Global Change and Governance, 3, 1-25.

BLATTMAN, C. and MIGUEL, E. (2010), “Civil War”, Journal of Economic Literature, 48, 3-57. 
BUHAUG, H., GATES, S. and LUJALA, P. (2009), "Geography, Rebel Capability, and the Duration of Civil Conflict", Journal of Conflict Resolution, 53, 544-569.

CASELLI, F. and COLEMAN II, W. J. (2012), "On the Theory of Ethnic Conflict", Journal of the European Economic Association (forthcoming).

CASELLI, F., MORELLI, M. and ROHNER, D. (2012), “The Geography of Inter-State Resource Wars”. (mimeo, LSE).

CASSAR, A., GROSJEAN, P. and WHITT, S. (2011), "Civil War, Social Capital and Market Development: Experimental and Survey Evidence on the Negative Consequences of Violence". (mimeo, University of San Francisco).

CEDERMAN, L. E. and GIRARDIN, L. (2007), "Beyond Fractionalization: Mapping Ethnicity onto Nationalist Insurgencies", American Political Science Review, 101, 173-185.

CHAMLEY, C. (1999), "Coordinating Regime Switches”, Quarterly Journal of Economics, 114, 869-905.

CHAMLEY, C. (2004), Rational Herds: Economic Models of Social Learning. (Cambridge: Cambridge University Press).

CHASSANG, S. and PADRO I MIQUEL, G. (2010), "Conflict and Deterrence under Strategic Risk", Quarterly Journal of Economics, 125, 1821-1858.

COLLIER, P. and HOEFFLER, A. (1998), "On Economic Causes of Civil War”, Oxford Economic Papers, 50, 563-573.

COLLIER, P. and HOEFFLER, A. (2004), "Greed and Grievance in Civil War”, Oxford Economic Papers, 56, 563-595.

COLLIER, P., HOEFFLER, A. and ROHNER, D. (2009), "Beyond Greed and Grievance: Feasibility and Civil War", Oxford Economic Papers, 61, 1-27.

COLLIER, P. and ROHNER, D. (2008), "Democracy, Development, and Conflict", Journal of the European Economic Association, 6, 531-540.

COLlETTA, N. and CULlEN, M. (2000), Violent Conflict and the Transformation of Social Capital: Lessons from Cambodia, Rwanda, Guatemala, and Somalia. (Washington: World Bank).

COOPER, R. and JOHN, A. (1988), "Coordinating Coordination Failures in Keynesian Models", Quarterly Journal of Economics, 103, 441-463.

DAL BÓ, E. and DAL BÓ, P. (2011), "Workers, Warriors, and Criminals: Social Conflict in General Equilibrium”, Journal of the European Economic Association, 9, 646-677.

DERCON, S. and GUTIERREZ-ROMERO, R. (2012), "Triggers and Characteristics of the 2007 Kenyan Electoral Violence", World Development, 40, 731-744.

DEROUEN, K. and BERCOVITCH, J. (2008), "Enduring Internal Rivalries: A New Framework for the Study of Civil War", Journal of Peace Research, 45, 55-74.

DIXIT, A. K. (2003), “Trade Expansion and Contract Enforcement”, Journal of Political Economy, 111, $1293-1317$.

DOYLE, M. and SAMBANIS, N. (2000), "International Peacebuilding: A Theoretical and Quantitive Analysis", American Political Science Review, 94, 779-801.

ELY, J. and VALIMAKI, J. (2003), "Bad Reputation”, Quarterly Journal of Economics, 118, 785-813.

ESTEBAN, J., MAYORAL, L. and RAY, D. (2012), "Ethnicity and Conflict: An Empirical Investigation", American Economic Review, 102, 1310-1342.

ESTEBAN, J. and RAY, D. (2008), "On the Salience of Ethnic Conflict", American Economic Review, 98, $2185-2202$.

ESTEBAN, J. and RAY, D. (2011), "Linking Conflict to Inequality and Polarization”, American Economic Review, 101, 1345-1374.

FEARON, J. (1995), "Rationalist Explanations for War”, International Organization, 49, 379-414.

FEARON, J. (2005), "Primary Commodity Exports and Civil War", Journal of Conflict Resolution, 49, 483-507.

FEARON, J. and LAITIN, D. (2003), "Ethnicity, Insurgency, and Civil War", American Political Science Review, 97, 75-90.

FERNANDEZ, R. (2012), "Culture as Learning: The Evolution of Female Labor Force Participation over a Century", American Economic Review (forthcoming).

FORTNA, V. (2004), "Does Peacekeeping Keep Peace? International Intervention and the Duration of Peace After Civil War", International Studies Quarterly, 48, 269-292.

GARTZKE, E. (1999), "War Is in the Error Term”, International Organization, 53, 567-587.

GATES, S. (2002), "Recruitment and Allegiance: The Microfoundations of Rebellion”, Journal of Conflict Resolution, 46, 111-130.

GLICK, R. and TAYLOR, A. (2010), "Collateral Damage: Trade Disruption and the Economic Impact of War", Review of Economics and Statistics, 92, 102-127.

GUISO, L., SAPIENZA, P. and ZINGALES, L. (2009), “Cultural biases in Economic Exchanges?”, Quarterly Journal of Economics, 124, 1095-1131.

GURR, T. (1970), Why Men Rebel. (Princeton: Princeton University Press).

HAUK, E. and SAEZ-MARTI, M. (2002), "On the Cultural Transmission of Corruption”, Journal of Economic Theory, 107, 311-315.

HOROWITZ, D. (2000), Ethnic Groups in Conflict (2nd edn). (Berkeley: University of California Press). 


\section{ROHNER ET AL. WAR SIGNALS}

INGELAERE, B. (2007), "Living the Transition: A Bottom-up Perspective on Rwanda's Political Transition" (Discussion Paper, University of Antwerp).

JACKSON, M. and MORELLI, M. (2007), "Political Bias and War", American Economic Review, 97, $1353-1373$.

JHA, S. (2008), "Trade, Institutions and Religious Tolerance: Evidence from India" (Stanford University Graduate School of Business Research Paper No. 2004).

KAUFMAN, S. (1996), "Spiraling to Ethnic War", International Security, 21, 108-138.

LICKLIDER, R. (1995), “The Consequences of Negotiated Settlements in Civil Wars, 1945-1993”, American Political Science Review, 89, 681-690.

LINDBECK, A. and WEIBULL, J. (1987), "Balanced-Budget Redistribution as the Outcome of Political Competition", Public Choice, 52, 273-297.

LUTTWAK, E. (1999), “Give War a Chance”, Foreign Affairs, July/August, 36-44.

MARTIN, P., MAYER, T. and THOENIG, M. (2008a), "Make Trade not War?”, Review of Economic Studies, 75, 865-900.

MARTIN, P., MAYER, T. and THOENIG, M. (2008b), "Civil Wars and International Trade", Journal of European Economic Association, 6, 541-550.

MONTALVO, J. and REYNAL-QUEROL, M. (2005), "Ethnic Polarization, Potential Conflict, and Civil Wars”, American Economic Review, 95, 796-816.

OLSSON, O. (2010), "Market Collapse in Vulnerable Environments: A Model Applied to Darfur" (mimeo, University of Gothenburg).

PALUCK, E. L. (2009), "Reducing Intergroup Prejudice and Conflict Using the Media: A Field Experiment in Rwanda", Journal of Personality and Social Psychology, 96, 574-587.

PALUCK, E. L. and GREEN, D. (2009), "Prejudice Reduction: What Works? A Review and Assessment of Research and Practice", Annual Review of Psychology, 60, 339-367.

PIKETTY, T. (1995), "Social Mobility and Redistributive Politics”, Quarterly Journal of Economics, 110, 551-584.

PINCHOTTI, S. and VERWIMP, P. (2007), "Social Capital and the Rwandan Genocide: A Micro-Level Analysis" (HiCN working paper 30).

PORTER, G., LYON, F., ADAMU, F. and OBAFEMI, L. (2010), "Conflict and Cooperation in Market Spaces: Learning from the Operation of Local Networks of Civic Engagement in African Market Trade", Human Organization, 69, 31-42.

POWELL, R. (2006), "War as a Commitment Problem", International Organization, 60, 169-203.

ROHNER, D. (2011), "Reputation, Group Structure and Social Tensions", Journal of Development Economics, 96, $188-199$.

ROHNER, D., THOENIG, M. and ZILIBOTTI, F. (2011), "Seeds of Distrust? Conflict in Uganda" (Working Paper Series, Department of Economics, University of Zurich, WP No. 54).

ROHNER, D., THOENIG, M. and ZILIBOTTI, F. (2012), "A Note on the "War Signal” Model with a Continuous Stochastic Process of War" (mimeo in progress, University of Zurich).

SAMBANIS, N. (2008), "Short- and Long-Term Effects of United Nations Peace Operations", World Bank Economic Review, 22, 9-32.

SPOLAORE, E. and WACZIARG, R. (2012), "War and Relatedness" (mimeo, Tufts University and UCLA).

TABELLINI, G. (2008), “The Scope of Cooperation: Values and Incentives”, Quarterly Journal of Economics, 123, 905-950.

THYNE, C. (2006), “ABC's, 123's, and the Golden Rule: The Pacifying Effect of Education on Civil War, 1980-1999”, International Studies Quarterly, 50, 733-754.

TORVIK, R. (2002), "Natural Resources, Rent Seeking and Welfare”, Journal of Development Economics, 67, 455-470.

UCDP (2012), "UCDP/PRIO Armed Conflict Dataset", dataset, www.pcr.uu.se/research/ucdp

UNICEF (2003), "Analysis of Nine Conflicts in Sudan" (Working paper, UNICEF).

VARSHNEY, A. (2001), "Ethnic Conflict and Civil Society”, World Politics, 53, 362-398.

VARSHNEY, A. (2002), Ethnic Conflict and Civic Life. Hindus and Muslims in India. (New Haven: Yale University Press).

WALTER, B. (2004), "Does Conflict Beget Conflict? Explaining Recurring Civil War", Journal of Peace Research, 41, 371-388.

WHAH, C. Y. (2010), “Towards Inter-Ethnic Business Development and National Unity in Malaysia” (CRISE Working Paper 73, University of Oxford).

WORLD VALUES SURVEY (2011), WVS Five Wave Aggregated File v.20090901, dataset, www.worldvaluessurvey.org/

YARED, P. (2010), “A Dynamic Theory of War and Peace”, Journal of Economic Theory, 145, 1921-1950. 